\title{
Aerodynamic investigations of a Vertical Landing Launcher configuration by means of Computational Fluid Dynamics and Wind Tunnel Tests
}

\author{
Jan $\operatorname{Vos}^{1}$ and Dominique Charbonnier ${ }^{2}$ \\ CFS Engineering, EPFL Innovation Park - Bat. A, 1015 Lausanne, Switzerland \\ Ansgar Marwege ${ }^{3}$ and Ali Gülhan ${ }^{4}$ \\ DLR Institute of Aerodynamics and Flow Technology, Supersonic and Hypersonic Technologies \\ Department, Linder Höhe, 51147 Cologne, Germany \\ Mariasole Laureti ${ }^{5}$ and Sebastian $\operatorname{Karl}^{6}$ \\ DLR Institute of Aerodynamics and Flow Technology, \\ Bunsenstrasse 10, 37073 Göttingen, Germany
}

In the RETALT (Retro Propulsion Assisted Landing Technologies) project critical technologies for two different vertical landing launcher configurations are investigated. For RETALT1, a Two Stage To Orbit launcher, only the first stage will be recovered using retro propulsion. A large number of wind tunnel experiments have been carried out at DLR in Cologne, while CFD simulations were made by CFS Engineering and DLR in Göttingen. This paper provides a detailed comparison of Wind Tunnel Experiments with CFD calculations in the hypersonic regime, with and without retro propulsion.

\section{Nomenclature}

$$
\begin{array}{ll}
C F D & =\text { Computational Fluid Dynamics } \\
W T T & =\text { Wind Tunnel Tests } \\
N S M B & =\text { Navier Stokes Multi Blocks } \\
R A N S & =\text { Reynolds-Averaged Navier Stokes } \\
A E D B & =\text { Aerodynamic DataBase } \\
A C S & =\text { Aerodynamic Control Surfaces } \\
C D & =\text { Drag coefficient } \\
C L & =\text { Lift coefficient } \\
C m & =\text { Pitching moment coefficient } \\
L E O & =\text { Low Earth Orbit } \\
G T O & =\text { Geostationary Transfer Orbit }
\end{array}
$$

\footnotetext{
${ }^{1}$ Director, jan.vos@cfse.ch, Senior AIAA member

${ }^{2}$ Research Scientist, current address: Destinus, Payerne, Switzerland, dominique.charbonnier@destinus.ch

${ }^{3}$ Research Scientist, ansgar.marwege@dlr.de

${ }^{4}$ Head of Department, ali.guelhan@dlr.de

${ }^{5}$ Research Scientist, mariasole.laureti@dlr.de

${ }^{6}$ Research Scientist, sebastian.karl@dlr.de
} 


\section{Introduction}

The Retro Propulsion Assisted Landing Technologies (RETALT) project, funded by the European Union Horizon 2020 program, has as objective to study critical technologies for re-usable launch vehicles. Two reference configurations were selected to be studied in detail in the project [1,2]: RETALT1 a Two Stage To Orbit (TSTO) Vertical Take-off Vertical Landing (VTVL) Launcher and RETALT2 a Single Stage To Orbit (SSTO) VTVL, see Fig. 1. RETALT1 is similar to the Falcon 9 by SpaceX, or the New Glenn by Blue Origin, but using only European technologies. RETALT1 should be able to transport 20 tons to a Low Earth Orbit (LEO), or 14 tons in the Geostationary Transfer Orbit (GTO). The RETALT2 configuration is similar to the DC-X and this configuration is mainly used as a technology test bed. A detailed overview of the project can be found in [1] and [2].
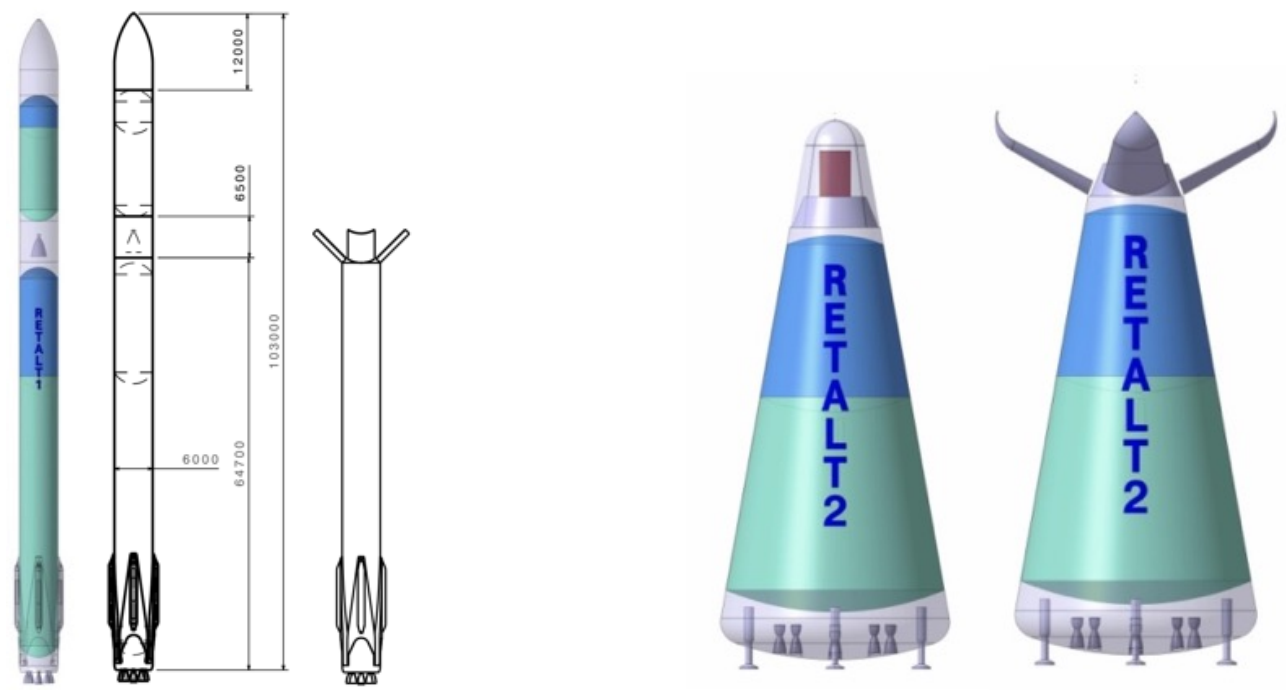

Fig. 1 RETALT1 TSTO configuration (left) and RETALT2 STSTO configuration (right).

This paper focuses on the Aerodynamics of the RETALT1 configuration, and in particular during the descent phase including retro-propulsion. RETALT1 is a Two Stage To Orbit (TSTO) heavy lift launcher using available propulsion technologies employing liquid oxygen and hydrogen (LOX/LH2). Both the first and second stage use an engine similar to the Vulcain 2 engine. The first stage is powered by 9 engines, and it is this stage that will be recovered using retropropulsion. Depending on the mission two options for recovery exist, which influence the descent trajectory. For low earth orbit (LEO) missions, the first stage can perform a Return To Launch Site (RTLS). For Geostationary Transfer Orbit missions this is not possible since this requires too much propellant [3] and a landing on a seagoing platform needs to be performed (Down Range Landing (DRL)).

When returning to the Launch site it is necessary to make a flip-over after stage separation and this is followed by a boost back burn using 3 engines. Then a second flip over is made to permit the use of the engines to reduce the landing speed. When a landing on a seagoing platform is foreseen only one flip-over maneuver is required. When entering the earth atmosphere, the aerodynamic control surfaces are deployed, and at an altitude of around $70 \mathrm{~km} \mathrm{a}$ first braking maneuver is made using 3 active engines (re-entry burn). This is followed by an aerodynamic phase, followed by the landing burn using only the central engine to decelerate the vehicle until touchdown. During the aerodynamic phase the vehicle is trimmed using the aerodynamic control surfaces. Different aerodynamic control surfaces were studied, and they had the requirement that they should be able to trim the vehicle flying at an angle of attack of $10^{\circ}$.

During the project a large number of wind tunnel experiments were performed at the supersonic and hypersonic facilities (TMK, H2K, VMK) at DLR in Köln. CFD simulations were made at CFS Engineering and at DLR Göttingen for the study of the aerodynamic control surfaces, for the generation of the Aerodynamic and Aero-thermodynamic data bases, and for the comparison of the results of Wind tunnel experiments with CFD.

This paper is organized as follows. Section III describes the wind tunnel facilities at DLR in Köln, Section IV describes the CFD solvers and discussed the grids used by CFS Engineering and by DLR Göttingen. Section V presents and discusses in detail the comparison of Wind tunnel experiments with CFD computations. 


\section{DLR Wind Tunnel Facilities}

Several extensive wind tunnel test series were performed in the RETALT project at the DLR Department of Supersonic and Hypersonic Technologies in Cologne. The reentry burn of the RETALT1 configuration was simulated in the Hypersonic Wind Tunnel Cologne (H2K), the aerodynamic phase (purely aerodynamic descent without active engines) was simulated in the Trisonic Wind Tunnel Cologne (TMK) and the landing burn will be simulated in an upcoming test series in the Vertical Free-jet Facility Cologne (VMK) where hot oxygen hydrogen combustion will be used inside the model to simulate the exhaust plume. For this paper some results of the $\mathrm{H} 2 \mathrm{~K}$ test series were evaluated for the comparison with CFD.

\section{A. Hypersonic Wind Tunnel Cologne (H2K)}

The Hypersonic Wind Tunnel Cologne $(\mathrm{H} 2 \mathrm{~K})$ is a blow down wind tunnel facility with pressurized air down to vacuum with an axisymmetric test section with a diameter of $600 \mathrm{~mm}$. The air is passing through an electrical heater, a Laval nozzle, the test chamber, the diffusor and is ultimately released in a vacuum chamber. Mach numbers of 4.8, $5.3,6.0,7.0,8.7$ and 11.2 can be tested with several existing nozzles. With a variation of the total pressure and temperature, Reynolds numbers in the range of $2.0 \times 10^{6}$ and $20.0 \times 10^{6} \mathrm{~m}^{-1}$ can be tested. Quartz glass windows provide visual access to the test chamber for schlieren imaging. The model can be mounted on a motion control device such that alpha-polars can be run. Typical test durations are round $30 \mathrm{~s}$. Due to a common design of the model support for the H2K and the TMK, the same wind tunnel models can be used in both facilities. The facilities are described in more detail in Refs. [4], [5] and [6].

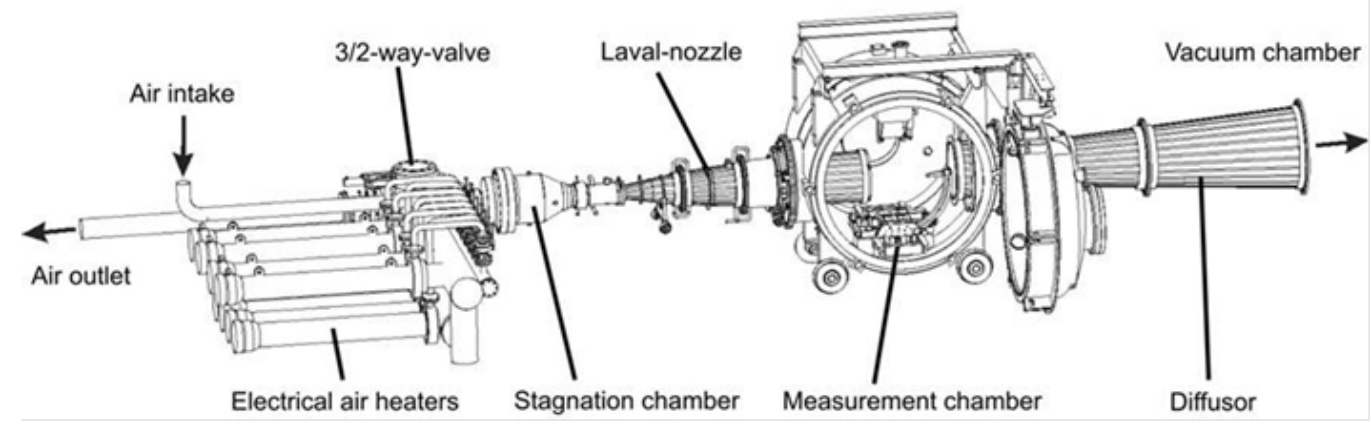

Fig. 2 Schematic of Hypersonic Wind Tunnel Cologne.

\section{B. Wind Tunnel Model and Instrumentation}

The RETALT1 wind tunnel model is depicted in Fig. 3, the model design is shown in Fig. 4. The model was designed in a manner that a short and a long version could be tested by adding or removing the blue cylindrical segment shown in Fig. 4. The two model versions are shown mounted in the wind tunnel in Fig. 3. While the long model version is used for force measurements, the short model version is intended for detailed analyses of the base flow with high frequency pressure measurements. In this paper results with the short model version will be discussed. The model has a scaling of $1 / 130$ with respect to the original RETALT reference configuration. For the simulation of the exhaust plume, air was blown out through a hollow model support string and a model Laval nozzle (see Fig. 4). Various nozzle segments were manufactured for the test of different engine combinations, i.e. one active engine or three active engines, and different engine deflection angles. The nozzle was designed with an expansion ratio of 2.5. This expansion ratio resulted after a trade-off of maximum pressures feasible in the model, maximum realizable thrust coefficients in the wind tunnel and representativeness of the exit pressure ratio at the model nozzle exit. The model can be equipped with a tubular 4 components balance. In the runs presented here the model was however solely equipped with pressure sensors. The locations of the high frequency pressure sensors are shown in Fig. 5. The pressure sensors were distributed in three measurement planes. One close to the interstage (closed in Fig. 5) (plane 1), one close to the folded landing legs (plane 2) and one at the model base (plane 3). Furthermore, the sensors were numbered in the clockwise direction viewing the model at the model base. This is represented by the second index. The third index for the sensors on the base plane defines the radial positioning from a position close to the center with index 1 to the outermost sensor with index 3 . 


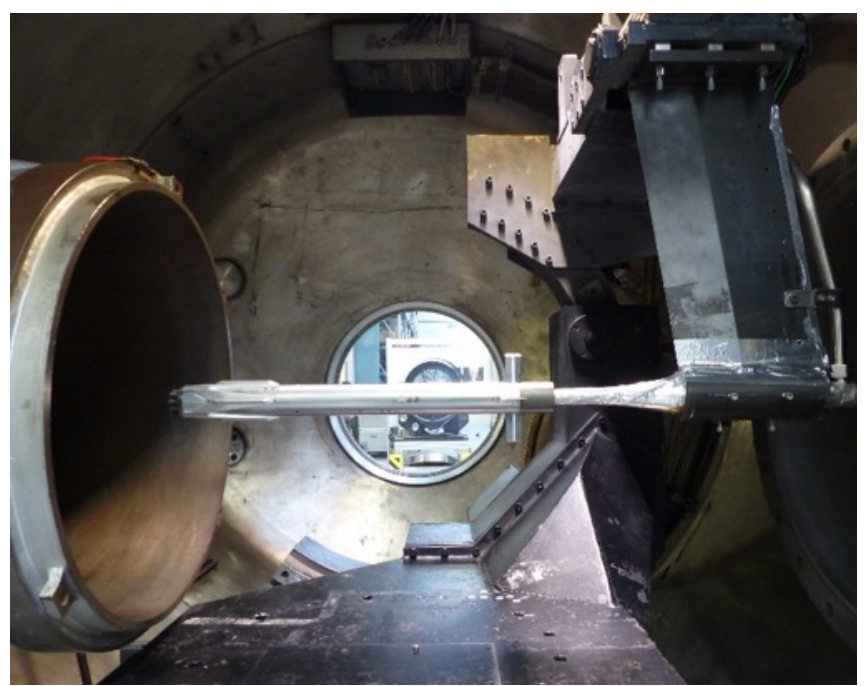

a) Long model version

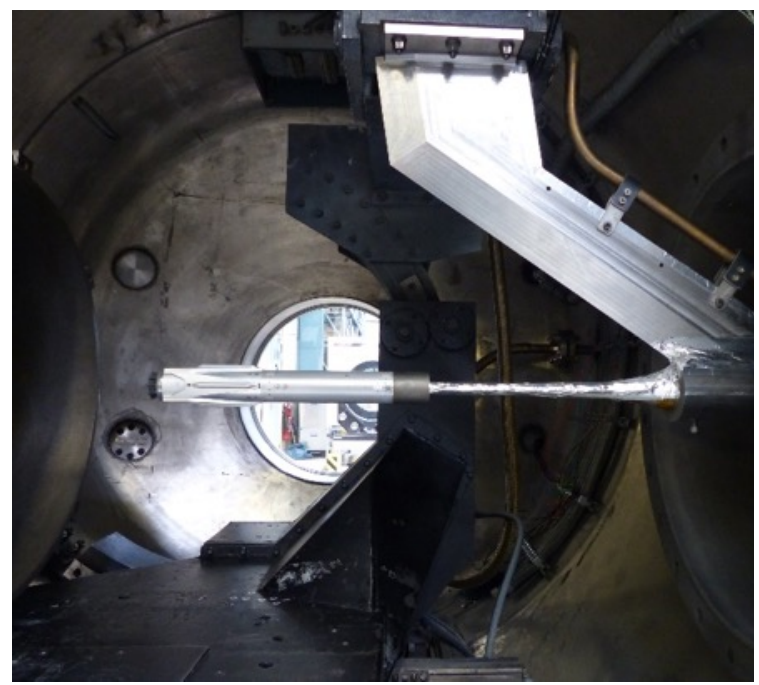

b) Short model version

Fig. 3 RETALT1 wind tunnel mounted in H2K.

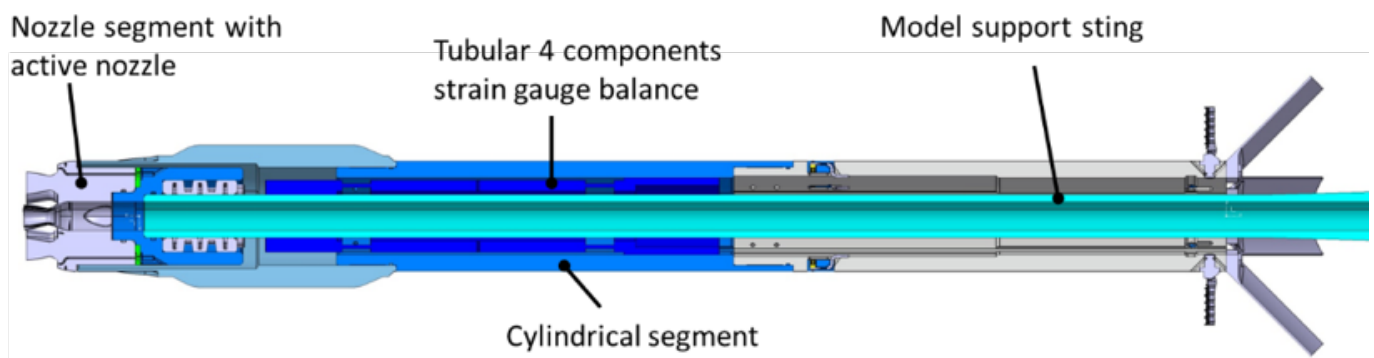

Fig. 4 RETALT1 wind tunnel model design.
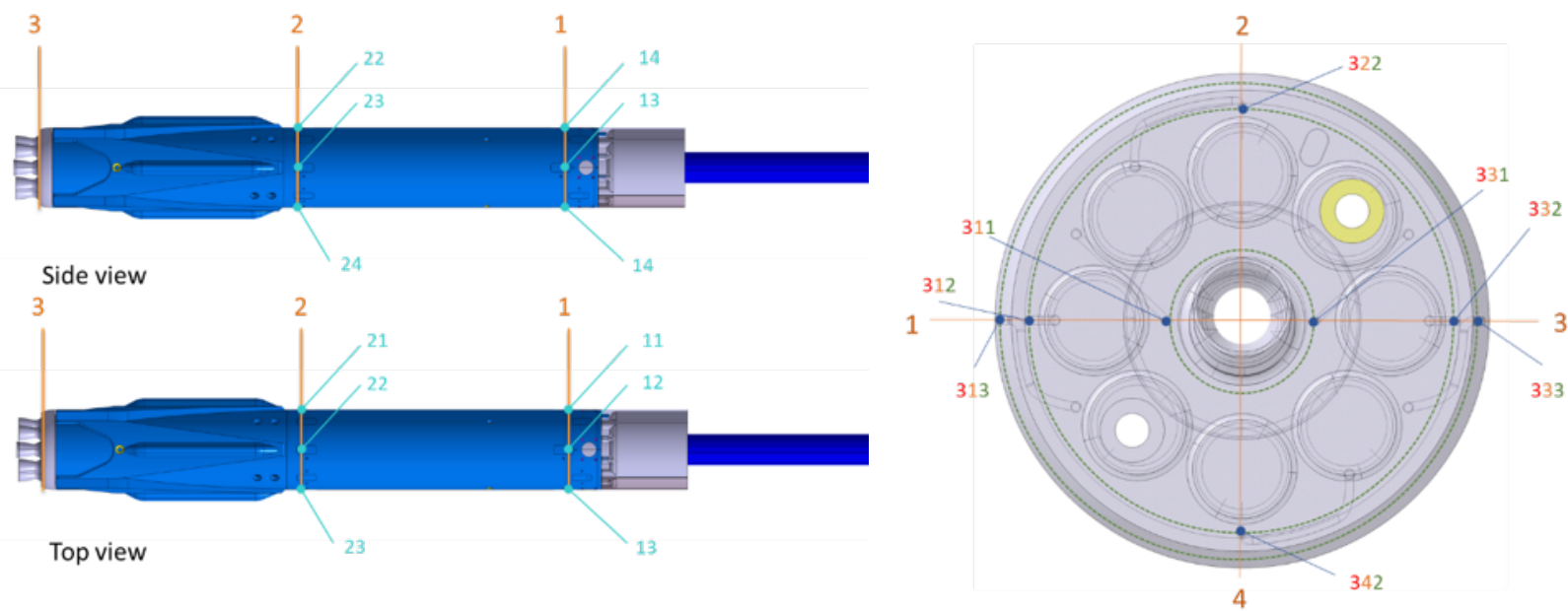

Fig. 5 RETALT1 distribution of pressure sensors. 


\section{Description of the CFD Solvers and the meshes used}

\section{NSMB CFD solver}

The CFD simulations carried out by CFS Engineering were made using the Navier Stokes Multi Block solver NSMB which is developed in a consortium composed of different universities and industries [7]. NSMB is a cellcentered finite volume solver using multi block structured grids. The code has a parallel and a vectorial structure and it can run on high-performance computers to solve a wide range of industrial aerodynamics design problems, and is mainly used for aeronautics and aerospace applications since more than 30 years.

To simplify the mesh generation for complex geometries the patch grid and chimera method are available in the solver. NSMB also includes remeshing algorithms that are employed for bow shock capturing for hypersonic flow problems. A large variety of turbulence models that are standard in the aeronautical and aerospace industry are available in the solver. For the RETALT1 configurations investigated, the one-equation Spalart-Allmaras [8] has been selected as the main turbulence model to be used; some calculations were made using k- $\omega$ Menter Shear Stress model [9] to assess the influence of the turbulence model.

NSMB includes a large variety of chemistry models for hypersonic applications. The chemistry modelling for the simulations at flight conditions including retro-propulsion is based on a thermally perfect gas assumption, with a mixture of 9 species (Nasa9 polynomial species). Mass fraction of species in the main flow (N2, O2) and in the exhaust gas $(\mathrm{H} 2 \mathrm{O}, \mathrm{OH}, \mathrm{H} 2, \mathrm{O} 2, \ldots)$ are applied as boundary conditions for computations with one or three engines active. The engine conditions are applied at the throat of the nozzles of the active engines.

\section{Mesh generation for NSMB}

The ANSYS ${ }^{\circledR}$ ICEM CFD ${ }^{\mathrm{TM}}$ pre-processer tool was used to generate the multi-block structured grids needed by the NSMB flow solver.

The patched mesh approach as well as the Chimera overlapping technique were used to simplify the mesh generation. Using these techniques, it is possible to generate a structured grid for a baseline configuration composed of the main cylindrical body, the base plate with the engine nozzles and the folded landing legs. Other configurations (with/without different control surfaces) are obtained using rotations and displacements of partial grid elements (a set of structured blocks). These partial grid elements are then patched on the baseline grid, and permit to have a similar grid with the same mesh cells density for all unchanged components of the RETALT1 configuration. Across patched grid boundaries the mesh density was kept the same.

To resolve the viscous boundary layer, O-grid topologies with a geometric cell distribution were used closed to the solid walls (body and control surfaces). The first cell height in the wall normal direction was set to obtain a $\mathrm{y}^{+}$ value close to/below 1 to ensure the proper use of low-Reynolds turbulence modeling, and the growth ratio of the cells normal to the wall was typically set close to 1.2. Particular attention was paid also to the refinement of the mesh in the bow shock region for the computations in the supersonic and hypersonic regimes.

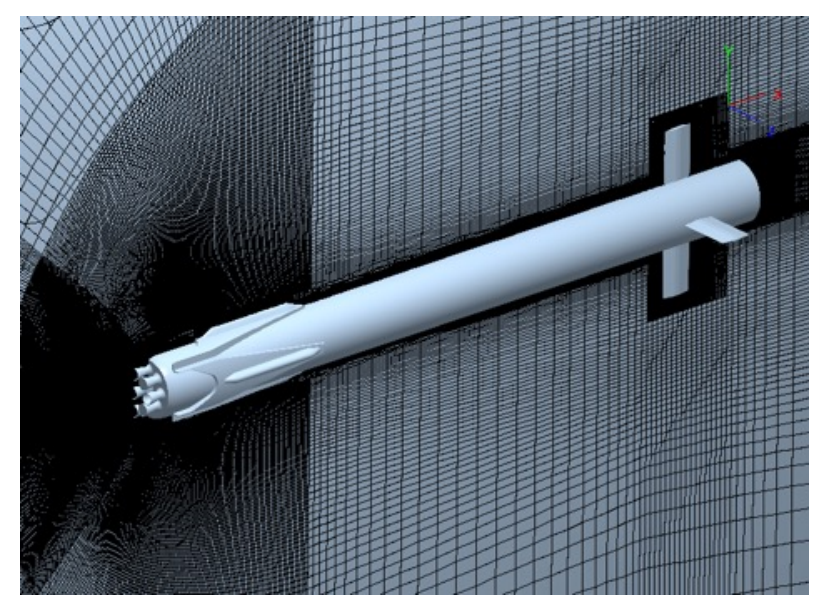

Fig. 6 Structured grid around RETALT1 configuration with planar fins.

Fig. 6 shows the typical structured grid used for the computations presented in this paper with a global overview of the mesh, where the refinement in the region of the bow shock (for super/hypersonic cases) is visible. Fig. 7 shows the grid in the region of the control surfaces for the three different type of control surfaces studied in the project. These 
control surfaces are patched in the baseline grid using the chimera technique. Deflection of the control surfaces can be easily obtained using rotations, and does not require the use of the mesh generation software. The structured mesh generation for the grid fins was a challenging task with a huge number of structured blocks (around 3000 per fin).
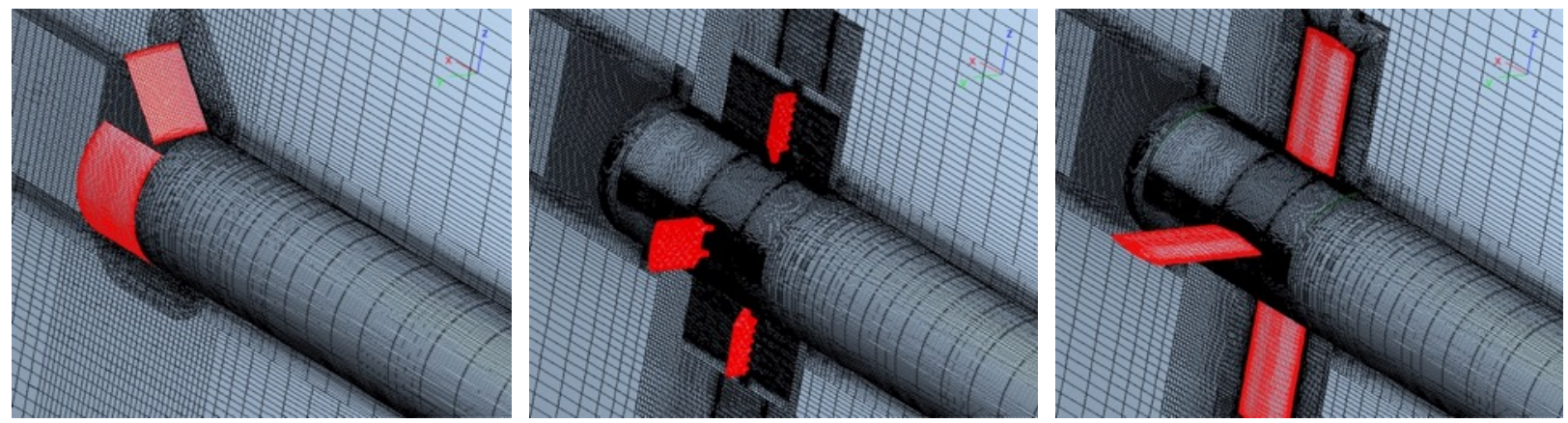

Fig. 7 Chimera structured grid for the different aerodynamic control surfaces: from left to right: petals, grid fins and planar fins.

For each configuration a fine grid was generated using at least 2 levels of multi grid. This allowed to generate a coarse grid using every $2^{\text {nd }}$ grid point in each direction. Most calculations were made on the coarse grids, each having in the order of 13 Million cells.

\section{E. TAU CFD solver}

The CFD simulations performed by DLR were carried out by means the structured-unstructured DLR NavierStokes solver TAU [10-11]. The TAU-code has been developed by the DLR Institute of Aerodynamics and Flow Technology and is a well-established and widely used tool for a broad range of aerodynamic and aero-thermodynamic problems for both scientific and industrial applications. The TAU CFD code is a second-order finite-volume flow solver for the Euler and Navier-Stokes equations in their integral forms. Various turbulence models are available, ranging from eddy viscosity to full differential Reynolds stress models [12] and options for hybrid RANS/LES. The code is adapted for large-scale simulations on massively parallel computers [11].

For the present investigations, the Spalart-Allmaras one-equation eddy viscosity model [8] has been employed. The AUSMDV flux-vector splitting scheme was applied together with MUSCL gradient reconstruction to achieve second-order spatial accuracy whilst maintaining a robust numerical treatment of strong discontinuities.

The thermodynamic modelling is based on a mixture of thermally perfect gases. The properties of the individual species are either computed from spectroscopic constants using partition functions that include an accurate representation of high temperature effects [13] or from NASA-Polynomials [14]. Appropriate mixture rules are applied to compute the thermodynamic properties depending on the local gas composition, pressure and density.

For the simulation of the RETALT1 vehicle, a chemically frozen mixture of air $(76 \% \mathrm{~N} 2$ and $24 \% \mathrm{O} 2$ by mass fraction) and engine exhaust gas $(97.7 \% \mathrm{H} 2 \mathrm{O}, 2 \% \mathrm{H} 2,0.2 \% \mathrm{OH}$ and tracer species) is considered. The additional heat release due to post-combustion of the fuel-rich exhaust gases in the flow field around the rocket configuration is neglected.

\section{F. Mesh Generation for TAU}

TAU uses a cell-vertex finite volume discretization. The unstructured primary grid consists of tetrahedral, prismatic, pyramidal and hexahedral elements. Boundary layers are discretized with prismatic layers with a wallnormal stretching ratio of approximately 1.25. The dimensionless first wall spacing $y+$ is close to 1 as required by the applied low-Re formulation of the Spalart-Allmaras RANS model. The grid density is enhanced in regions of particular interest and large flow gradients (e.g. plumes and the near-base recirculation). Available flow symmetries were used. Hence, quarter or half domains were applied for the computations with about $25 \mathrm{M}$ and $50 \mathrm{M}$ grid volumes (or primary grid points), respectively. Fig. 8 shows a view of the grid around the body including a zoom in the plume region, where a very fine grid is used to capture the plume. Fig. 9 shows a zoom of the base region clearly showing the nozzles and the refined applied in this region. 

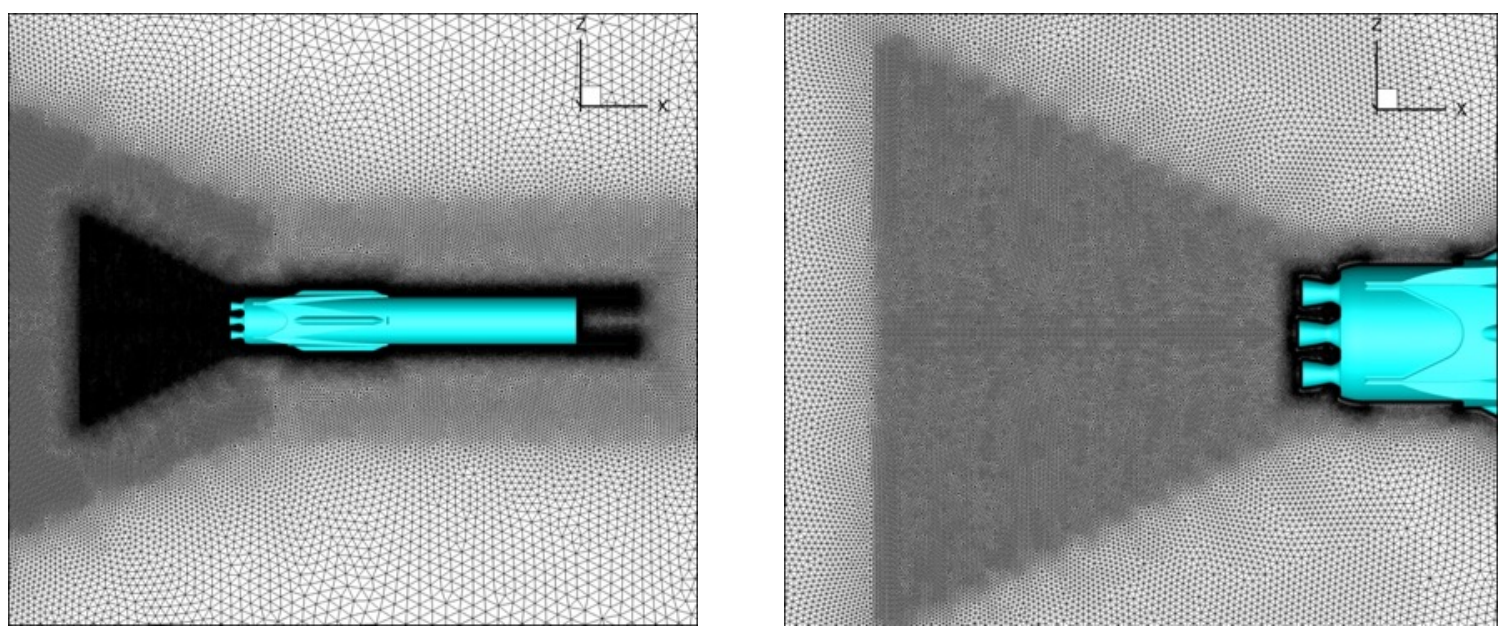

Fig. 8 External flow field grid including 2 refinement levels for a better representation of the plume, left: entire experimental configuration, right: zoom of the base region.

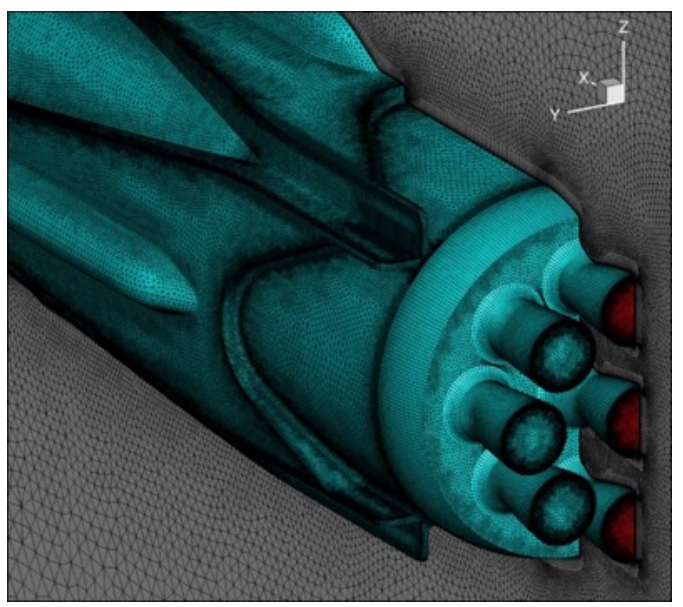

Fig. 9 Structured/unstructured grid around the lower part of RETALT1 experimental model.

\section{Comparison WT experiments and CFD calculations}

\section{A. Conditions}

Two engine layout configurations for the cases with 3 engines active were tested, and are shown Fig. 10. A prestudy for the preparation of the RETALT wind tunnel experiments in the H2K was performed in 2020 and its results were published in [15]. These tests showed that the maximum thrust coefficient that can be tested in hypersonic wind tunnels is limited by an increased interaction between the retro plume with the wind tunnel flow at increased thrust coefficients. This interaction can first be observed at the rear of the vehicle. Hence, for RETALT1 close to the interstage. Therefore, by monitoring the pressure sensors in plane 1, the highest possible thrust coefficients to be tested in the $\mathrm{H} 2 \mathrm{~K}$ could be determined. Based on these thrust coefficients which were 3.75 for the case with one active engine and 6.9 ( 3 times 2.3) for the case with 3 active engines the total pressure in the model (pCC) was defined. A nominal Mach number of 5.3 was selected as baseline Mach number due to smaller boundary layer in the wind tunnel nozzle at lower Mach numbers and therefore higher possible thrust coefficients. For the given total pressure and temperature after calibration of the Mach number with the Reynolds number this results in a Mach number of 5.29.

The conditions studied at this Mach number are summarized in Table 1, with $\mathrm{p} 0$ and $\mathrm{T} 0$ the freestream stagnation conditions, and pCC and TCC the engine total pressure and total temperature. In the CFD calculations the engines were modelled by imposing the total pressure and total temperature for the injection of cold air. 


\begin{tabular}{|c|c|c|c|c|c|c|c|c|c|c|}
\hline Computations & Model & Run & Engines & Alpha DSC $\left[{ }^{*}\right]$ & Configuration & Mach & po [bar] & TO $[\mathrm{K}]$ & pCc [bar] & $\mathrm{TCC}[\mathrm{K}]$ \\
\hline 1 & Short & 76 & 0 & 0 & 1 & 5.29 & 4 & 450 & 0 & 300 \\
\hline 2 & Short & 81,90 & 1 & 0 & 1 & 5.29 & 4 & 450 & 20 & 300 \\
\hline 3 & Short & 84,92 & 1 & 10 & 1 & 5.29 & 4 & 450 & 20 & 300 \\
\hline 4 & Short & 93 & 3 & 0 & 1 & 5.29 & 4 & 450 & 12.3 & 300 \\
\hline 4 & Short & 101 & 3 & 0 & - & 5.29 & 4 & 450 & 12.3 & 300 \\
\hline 5 & Short & 96 & 3 & 10 & 1 & 5.29 & 4 & 450 & 12.3 & 300 \\
\hline 6 & Short & 107 & 3 & 10 & - & 5.29 & 4 & 450 & 12.3 & 300 \\
\hline
\end{tabular}

Table 1: RETALT1 configurations studied at Mach=5.29.

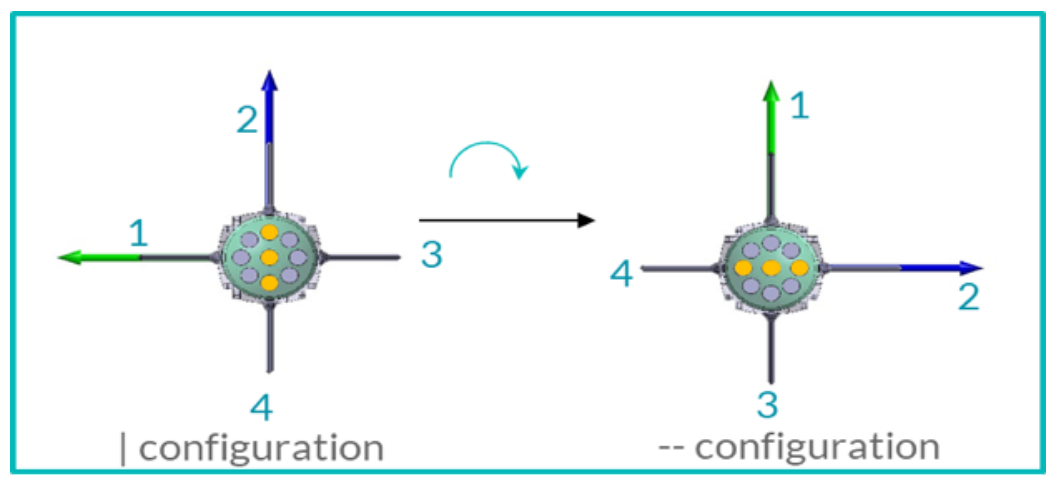

Fig. 10 Engine Layout Configurations studied.

\section{B. CFD simulations}

CFD simulations were made using both the NSMB and TAU CFD codes. Both codes employed the SpalartAllmaras turbulence model. The NSMB simulations were made using the central scheme, while the TAU simulations were made using a $2^{\text {nd }}$ order upwind scheme. Fig. 11 shows the grids in the base region used by the two solvers.
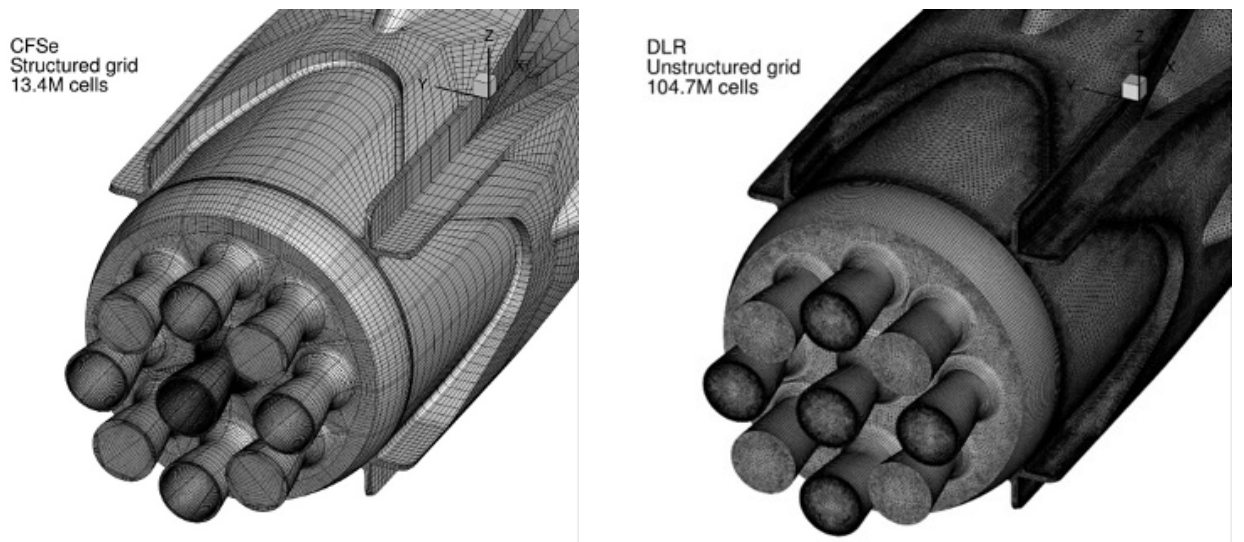

Fig. 11 Grids in the base region showing the engines, left: structured grid used by NSMB, right: unstructured grid used by TAU.

\section{Comparison with Schlieren pictures}

1. Engine off

Fig. 12 shows a Schlieren pictures comparison of the Wind tunnel measurements with the 2 CFD simulations for the case with engines off. As can be seen the bow shock and internal shocks are well captured. The TAU calculation shows some stronger internal shocks which are not visible in the experiment and in the NSMB calculations. 

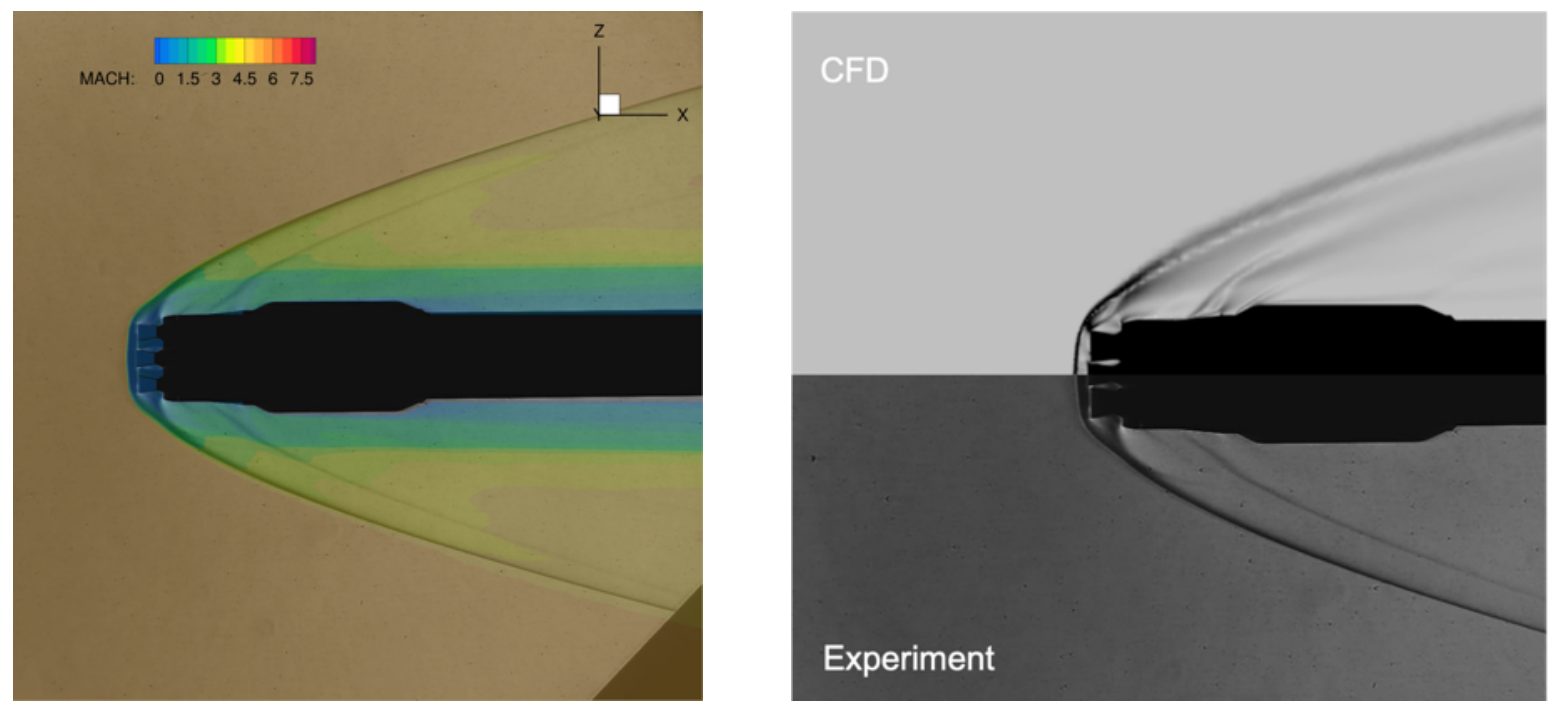

Fig. 12 Comparison with Schlieren pictures, engines off, $A 0 A=0^{\circ}$, left: NSMB CFD simulation, right: TAU CFD simulation (top) and Experiment (bottom).

\section{Central engine active}

Fig. 13 shows the computed Mach numbers using the TAU and NSMB codes, with the Schlieren picture imposed. One can see that for both CFD calculations the bow shock is slightly farther away from the body than in the experiment, but the terminal shock Mach disk is well captured. Comparison of the CFD results show some small differences in plume shape. Fig. 14 summarizes the flow structure in the plume region, which is complex due to the incoming hypersonic flow that encounters the jet flow from the engine. As a result, the plume is widened, and the bow shock position is pushed away from the body compared to the engine off case. Just downstream of the bow shock wave a stagnation surface appears where the velocity of the incoming flow equals the velocity of the jet coming out of the engine. Finally, a Mach disk is formed at the end of the plume and starts the subsonic region in the direction of the stagnation surface.

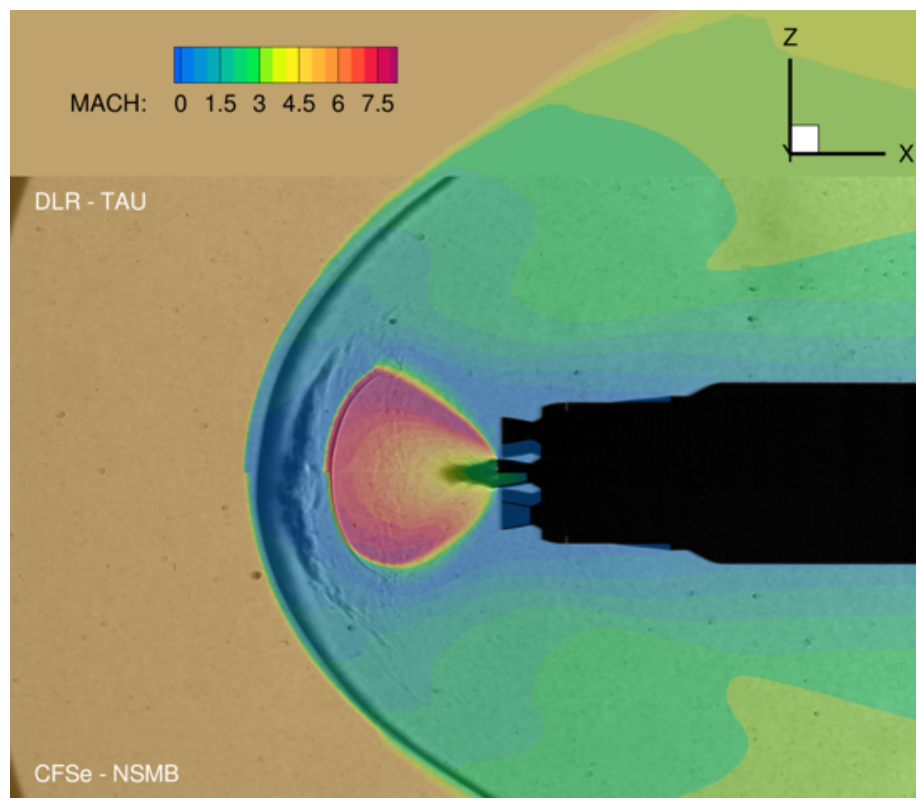

Fig. 13 Comparison with Schlieren pictures, central engine active, $\mathbf{A o A}=0$. 


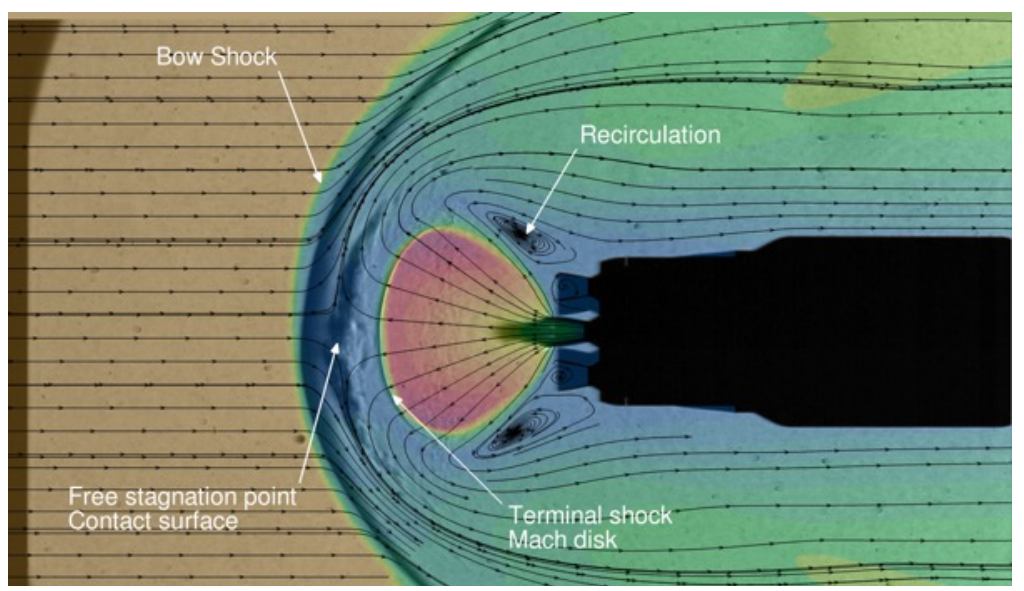

Fig. 14 Flow structure, central engine active, $\mathbf{A o A}=0$.

A sensitivity analysis was made to study why the computed and measured bow shock position differ slightly. A variation of $\pm 5 \%$ in the free stream Mach number and in the total pressure at the nozzle throat was made, and the results are shown in Fig. 15. One can observe that by increasing the Mach number with $5 \%$ the computed bow shock is closer to the bow shock position in the Schlieren image, but the position of the terminal shock Mach disk has moved too, and is farther away from the measured position. Increasing the nozzle pressure with $5 \%$ moves the bow shock farther away from the body, and the same can be observed when reducing the free stream Mach number. Reducing the nozzle pressure with $5 \%$ moves the bow shock slightly closer to the body.
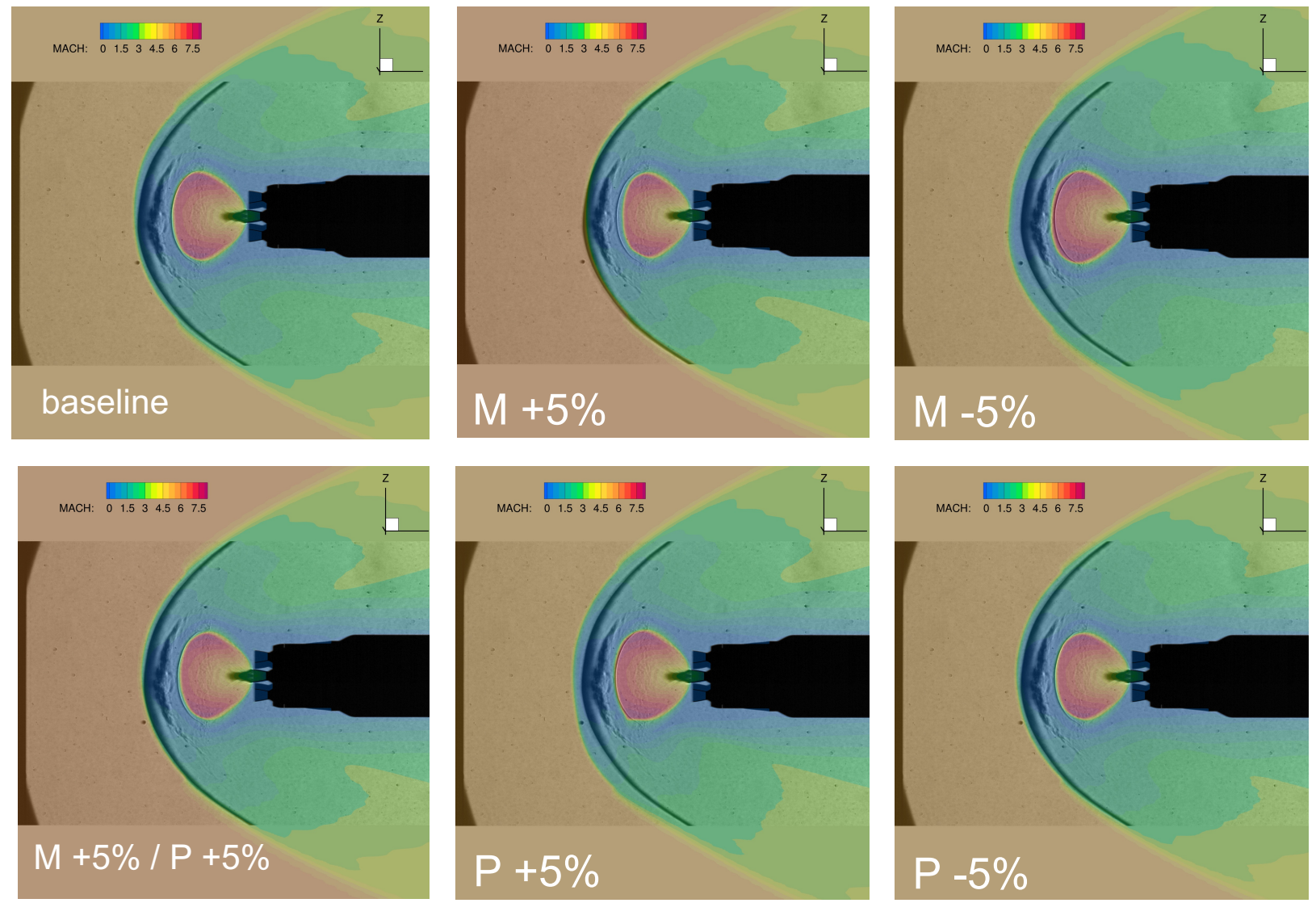

Fig. 15 Sensitivity analysis by varying the free stream Mach number and the engine total pressure, central engine active, $\mathrm{AoA}=0^{\circ}, \mathrm{CFD}$ results with superimposed Schlieren pictures. 
Finally increasing both the free stream Mach number as well as the nozzle pressure gives a slightly better position of the computed bow shock, but the position of the terminal shock Mach disk is slightly off. This sensitivity analysis showed clearly the interplay between at one hand the free stream conditions, and at the other hand the engine conditions, and it is this interplay which determines the bow shock position and the terminal Mach disk in the flow. Note that the $\pm 5 \%$ variation of the Mach number and the pressure in the wind tunnel model are larger than the expected uncertainties in the measurements. In the future a detailed uncertainty analysis of the wind tunnel data will be performed to assess the measurement uncertainties.

Fig. 16 shows the results for an Angle of attack of $10^{\circ}$. As can be seen the plume has become asymmetric. Some differences in computed shape of the plume can be observed when comparing the TAU and NSMB results.
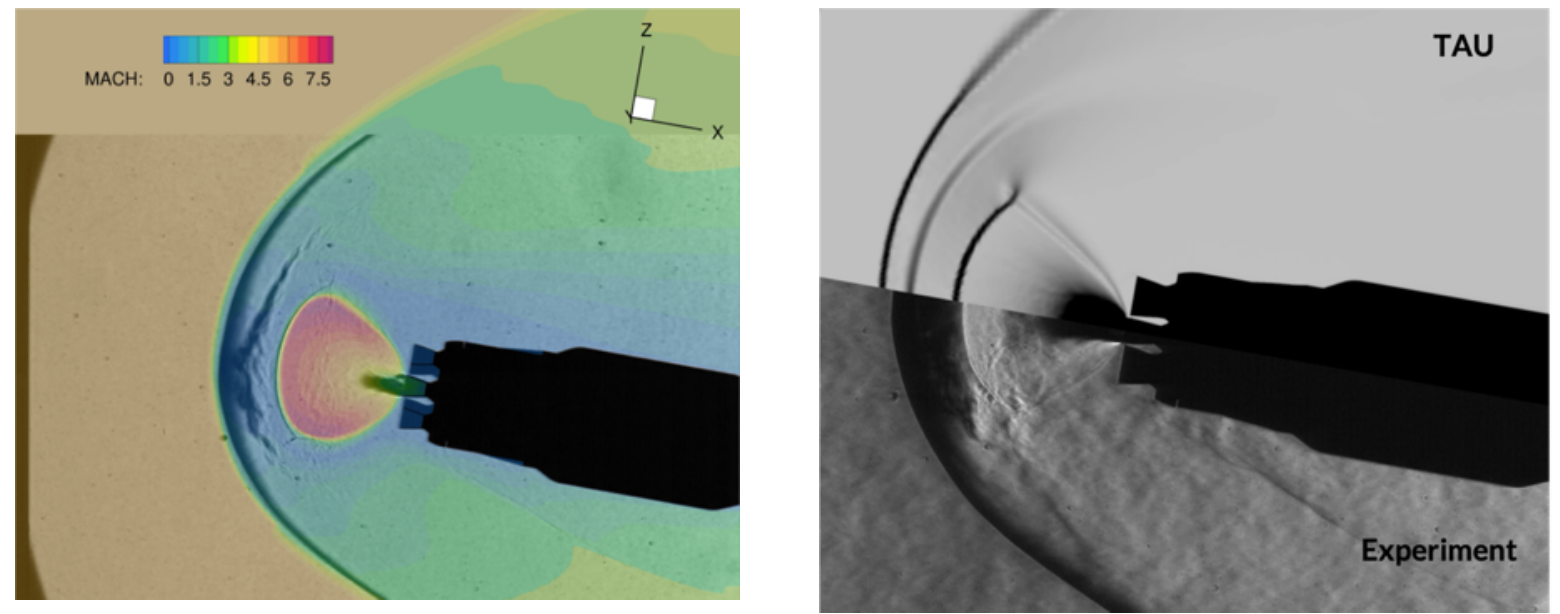

Fig. 16 Comparison with Schlieren pictures, central engine active, $A 0 A=10^{\circ}$, left: NSMB CFD simulation with superimposed Schlieren picture, right TAU CFD simulation (top) and Experiment (bottom).

\section{3 engines active}

The experiments using 3 engines active showed unsteady flow behavior. This was not found in the CFD results obtained using NSMB. Fig. 17 shows the comparison of CFD results with the Schlieren pictures, and a comparison of the TAU and NSMB results. The comparison with Schlieren pictures shows some wavy patterns in the experimental results, indicating the already mentioned flow unsteadiness. The comparison of CFD results showed large differences in the position of the bow shock, and in the shape of the plume.
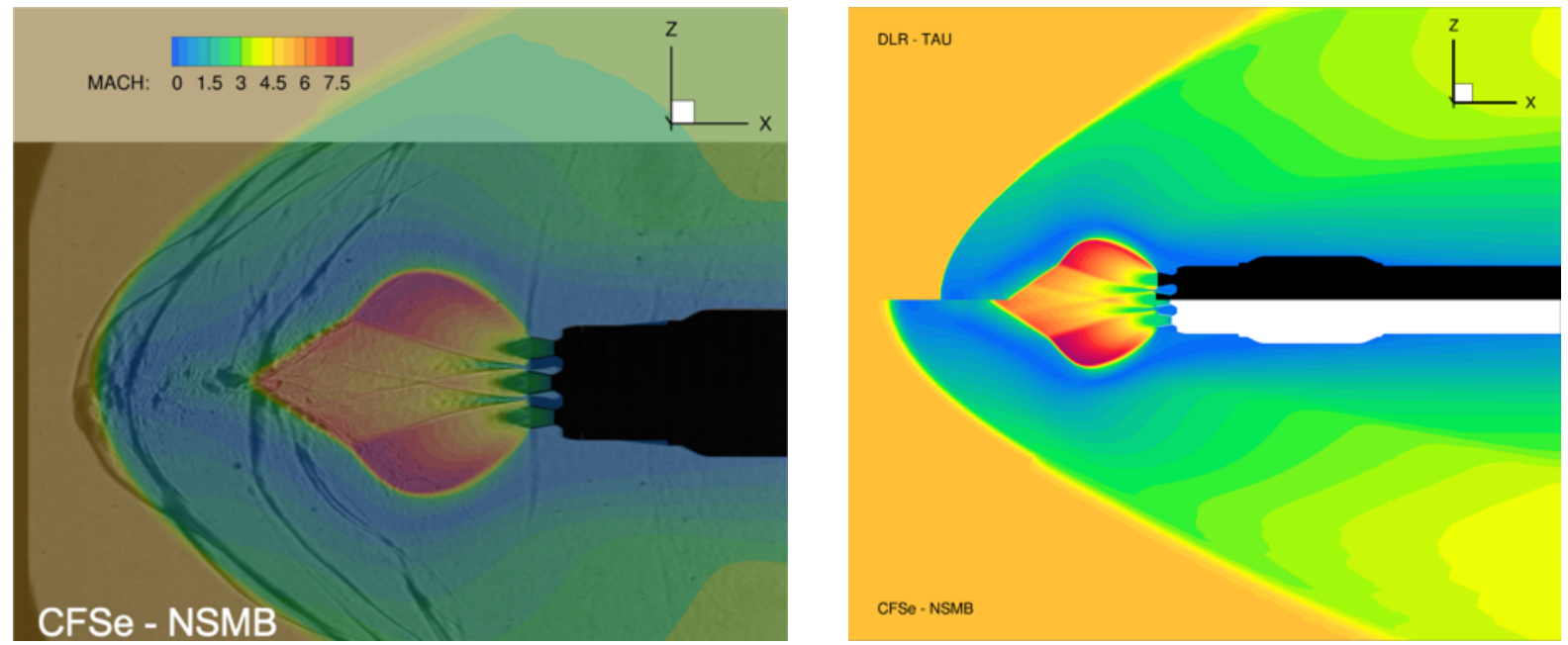

Fig. 17 Three engines active $A 0 A=0^{\circ}$, comparison with Schlieren pictures (left), comparison TAU and NSMB CFD results (right). 
To study the influence of the space discretization scheme a calculation was made with NSMB using the $2^{\text {nd }}$ order AUSMDV upwind scheme instead of the central scheme. The calculation with the AUSMDV scheme was more difficult to converge and required lower CFL numbers. The results are shown in Fig. 18, as well as the comparison with the result obtained using the TAU code. One can conclude that for this particular case the choice of the space discretization scheme has a substantial influence on the shape of the plume and the position of the bow shock wave.
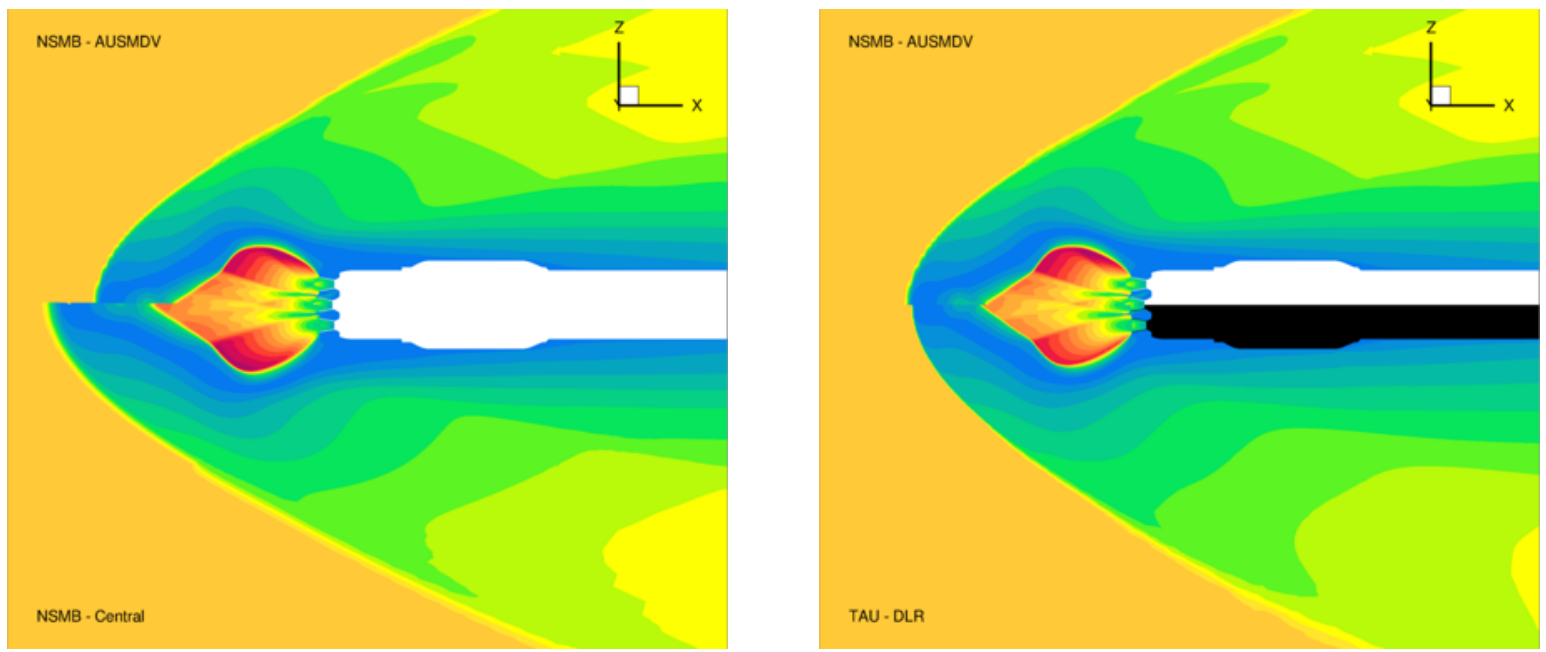

Fig. 18 Comparison space discretization schemes, three engines active, $\mathbf{A o A}=0$, left: NSMB calculations using the AUSMDV scheme and central scheme, right: comparison NSMB and TAU both using the AUSMDV scheme.

DLR performed a turbulence and grid sensitivity analysis, and the results are shown in Fig. 19. Some small differences can be observed, as to be expected, and in particular the bow shock position is slightly farther away from the body when using the k- $\omega$ SST model. The differences in results obtained using the coarse and fine grid are small.
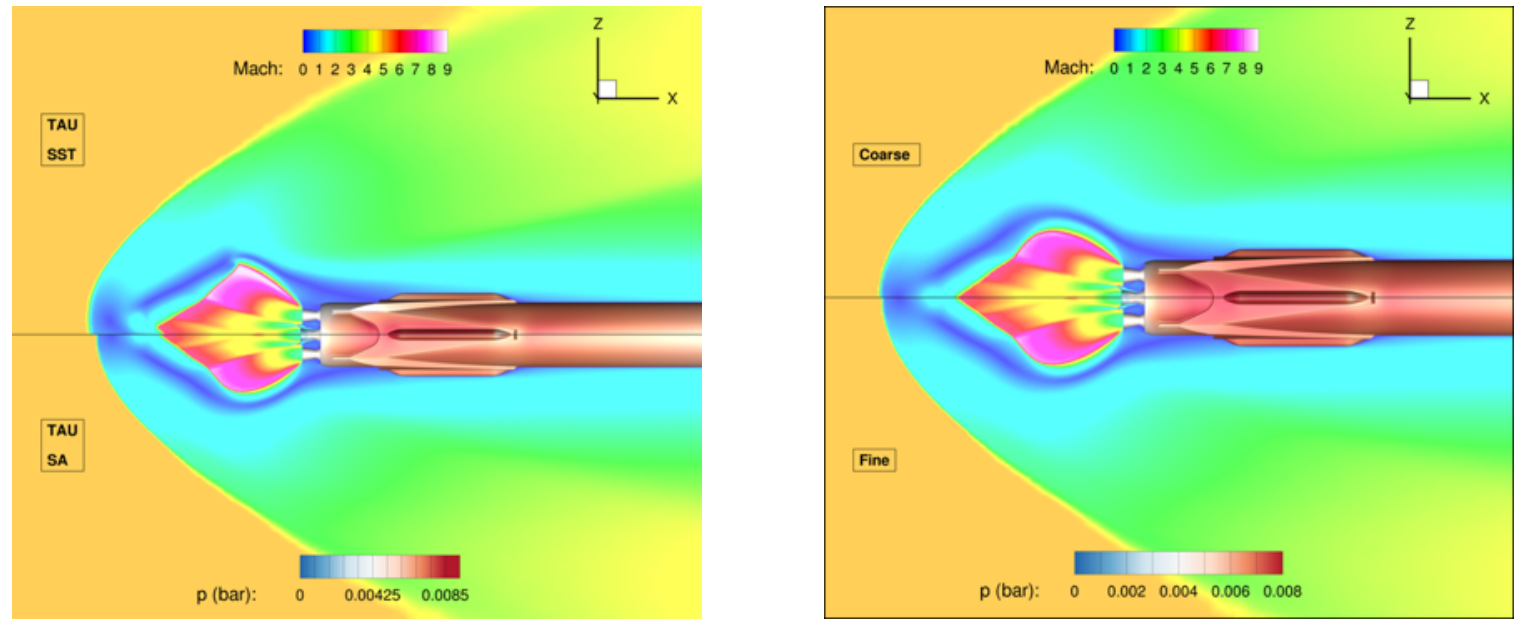

Fig. 19 Three engines active $A 0 A=0^{\circ}$, TAU CFD results, left: influence turbulence modeling, right: influence grid size using the Spalart-Allmaras turbulence model.

DLR also performed a Large Eddy Simulation for this case, and the averaged LES result is compared with the RANS CFD results in Fig. 20. As can be seen the bow shock position as well as the terminal Mach disk position are much farther away from the body for the LES calculation. It is interesting to see that the position of the terminal Mach disk calculated using RANS NSMB with the central scheme is closer to the LES result than the result of the RANS simulation using TAU using the upwind scheme. 

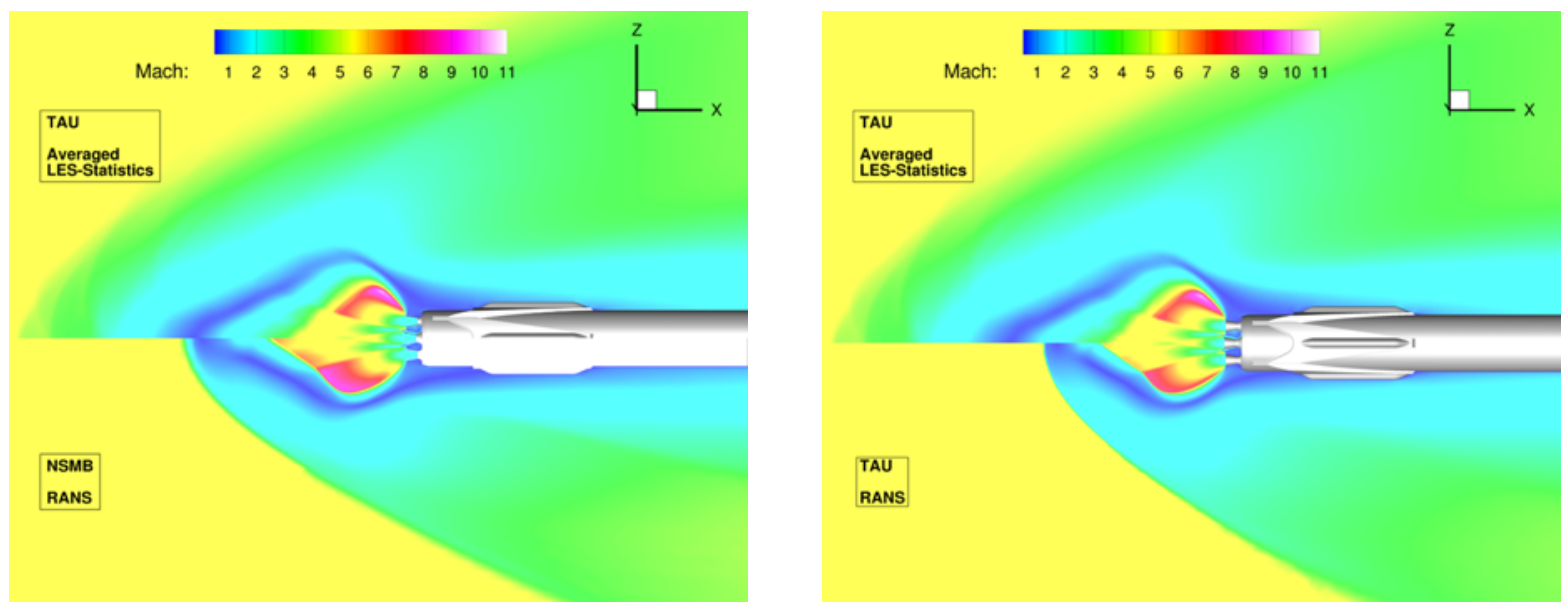

Fig. 20 Three engines active AoA $=0^{\circ}$, comparison averaged LES (on top) with RANS (bottom), left: comparison with RANS NSMB, right: comparison with RANS TAU.

\section{Comparison with pressure sensors}

The wind tunnel model was equipped with a large number of sensors in the base region and around the body (see Fig. 5). The pressures were sampled at a frequency of $50 \mathrm{kHz}$. For the comparison with the CFD computations they were filtered with a low pass filter with a cut-off frequency of $4 \mathrm{~Hz}$.

\section{Engine off}

The wind tunnel model was equipped with a large number of sensors in the base region and around the body, see Fig. 5. Fig. 21 shows a comparison of the pressure in the base region and along the body. In the base region there is a good comparison between Wind tunnel data and CFD, except for the sensors 313 and 333 where the CFD results give substantially higher pressures. These sensors are located on the side of the base plane, which explains the low values of the pressure here. Along the body both CFD results are in good agreement, but predict higher pressures than experimentally observed.
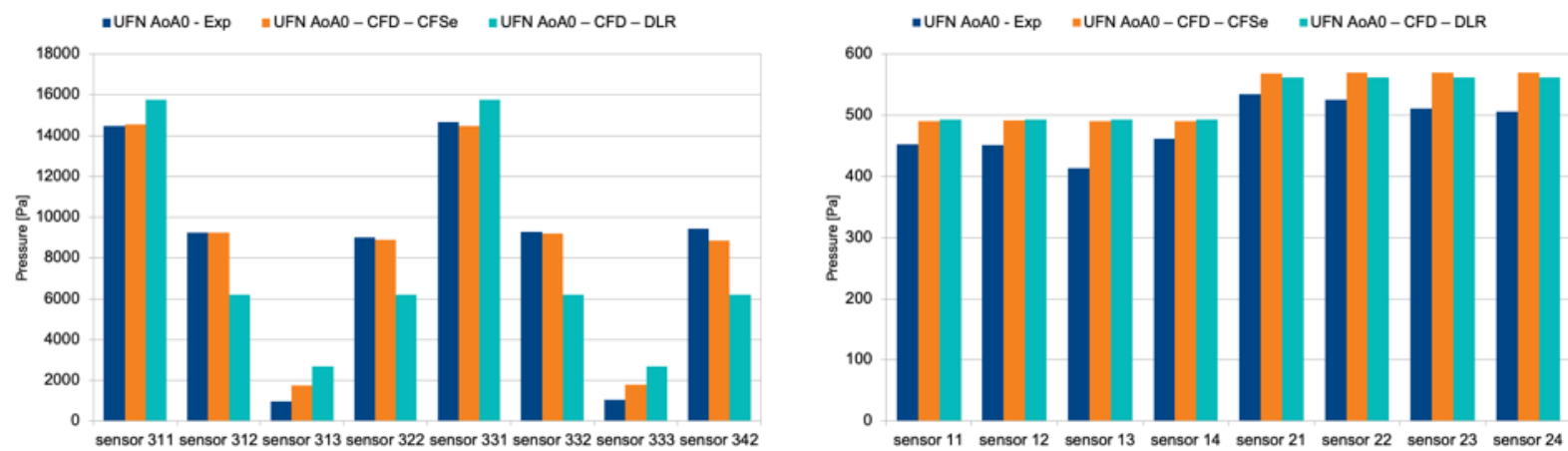

Fig. 21 Comparison pressure data Wind Tunnel Experiments and CFD, engine off, $A 0 A=0^{\circ}$ left: base region, right: in two $x=$ constant planes along the body.

Fig. 22 shows the computed pressure in the symmetry plane along the body. Differences can be observed in the base region and in the part along the body until the start of the landing legs (around $x=-0.28 \mathrm{~m}$ ). Further downstream the computed pressure data are in good agreement. 


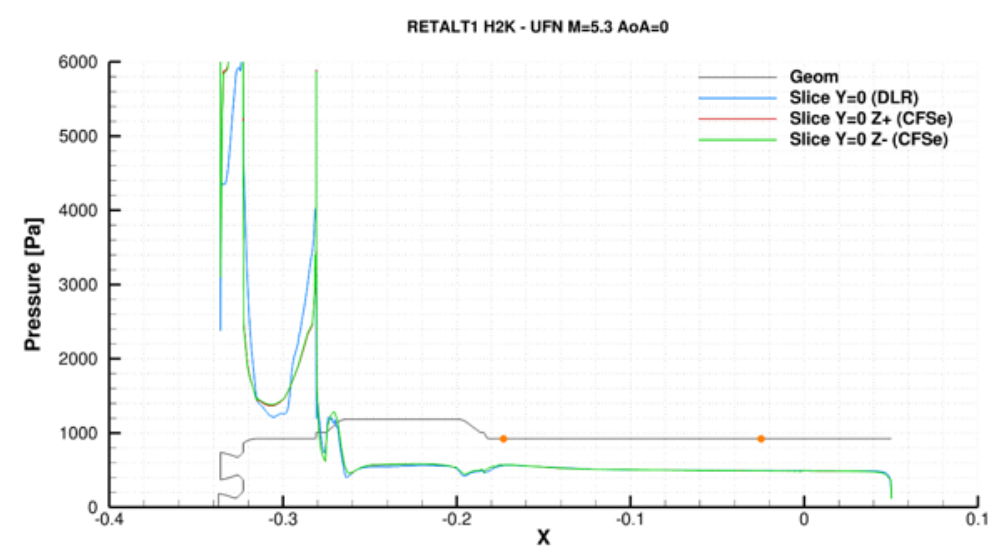

Fig. 22 Computed pressure along the body in the symmetry plane, engine off, $\mathrm{AoA}=0^{\circ}$.

Fig. 23 shows the skin friction lines on the body and in the base region, with the approximative location of the pressure sensor indicated by a red dot in the left picture. The right picture clearly shows the complexity of the flow, with several flow separations visible that are also incurred through the landing legs. In the base plane the pressure is an order of magnitude higher than along the body, and forces the flow over the sides of the base plane, with several flow separations just before the flow goes over the side. The location of the pressure sensors 313 and 343 are in the regions where the flow has re-attached and the boundary layer starts to grow, and this might be the reason why the computed and measured pressure values differ.
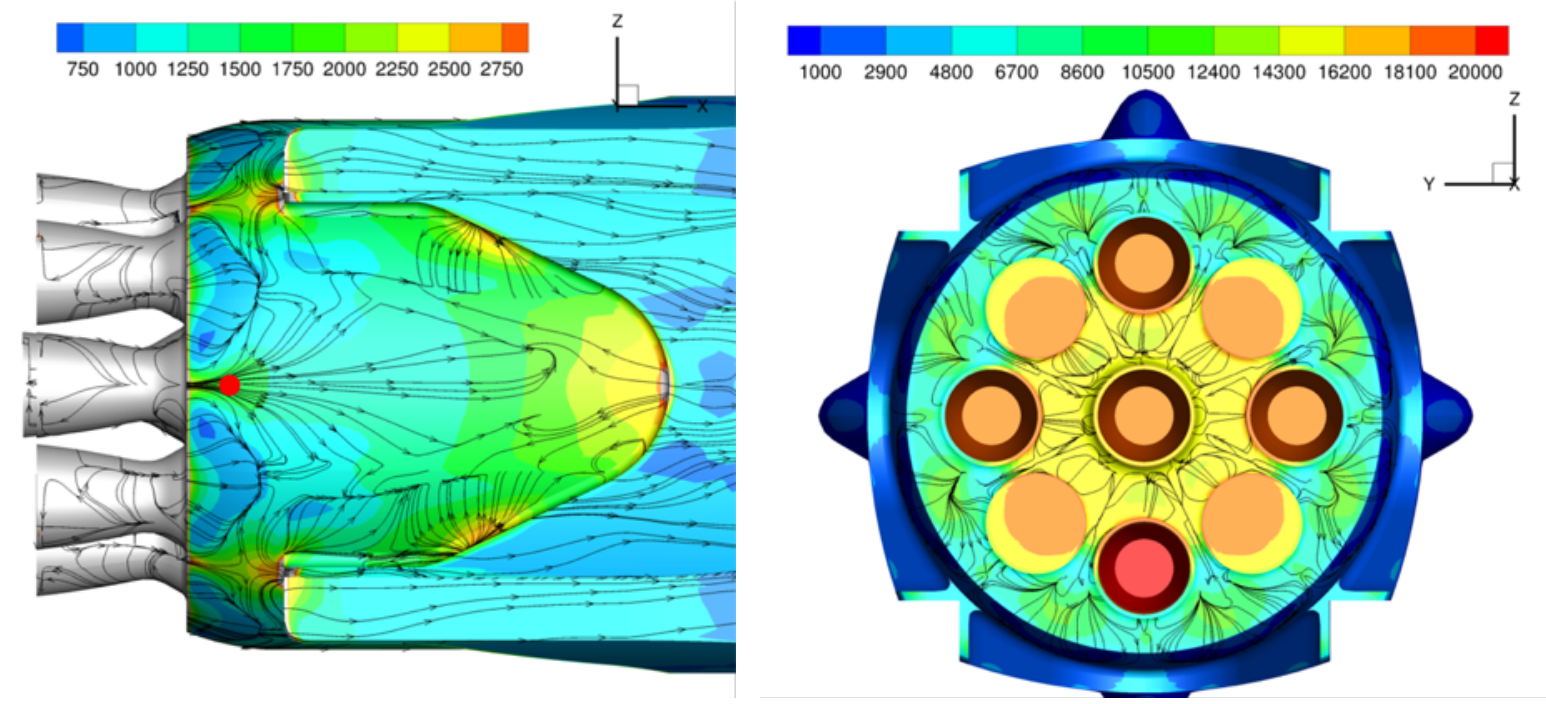

Fig. 23 Skin friction lines and pressure contours (in Pa) on the body and in the base region, engine off, $\mathrm{AoA}=0^{\circ}$, pressures below and beyond the scale are colored in grey.

\section{Central engine active}

Fig. 24 shows the comparison wind tunnel data - CFD for the experiments with the central engine active, for the two angles of attack measured. Both plots include the data along the body (sensors 11-24), and in the base region (sensors 311-342). For the case $\mathrm{AoA}=0^{\circ}$, the measured pressures along the body are higher than the computed pressures. The opposite is the case for the condition $\mathrm{AoA}=10^{\circ}$. For both angles of attack there is a good agreement among the CFD results along the body. In the base region larger differences between experimental and CFD results can be observed. For almost all pressure sensors in this region the NSMB calculations yields higher pressures. 

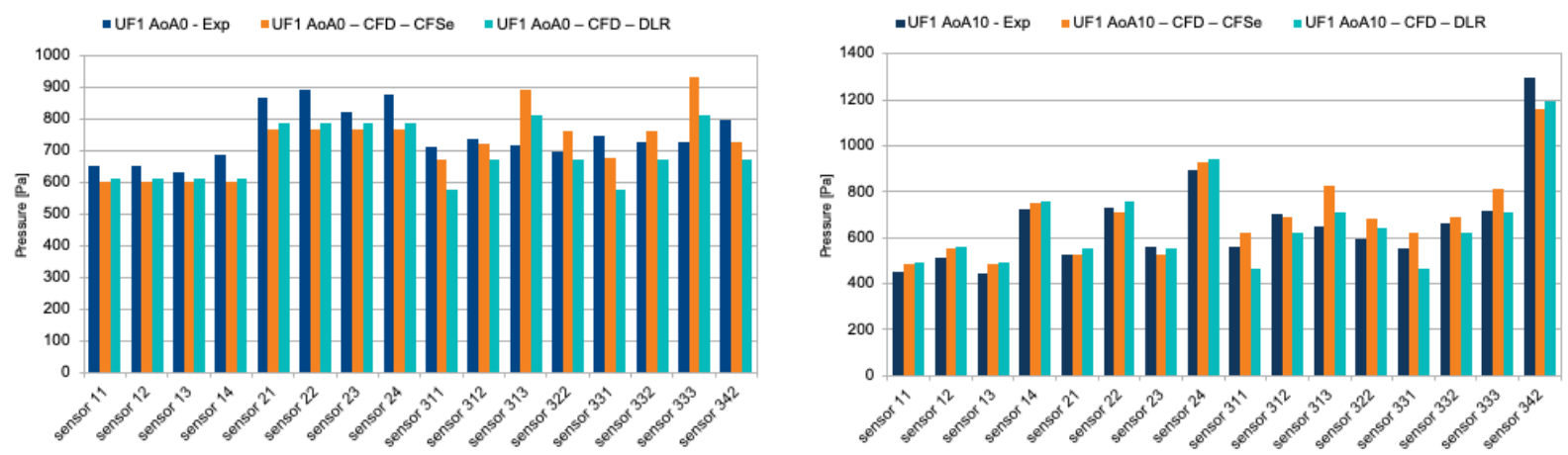

Fig. 24 Comparison pressure data Wind Tunnel Experiments and CFD, central engine on, left: $\mathrm{AoA}=0^{\circ}$, right: $\mathrm{AoA}=10^{\circ}$.

Fig. 25 shows the computed pressure along the body in the symmetry plane for the calculation at an angle of attack of $10^{\circ}$. For both calculations the results are extracted on both the windward and leeward side of the body. On the leeward side the computed pressures are in good agreement downstream of the start of the landing legs (around $\mathrm{x}=-$ $0.28 \mathrm{~m}$ ). On the wind ward side larger differences can be observed that disappear downstream of the end of the landing legs.

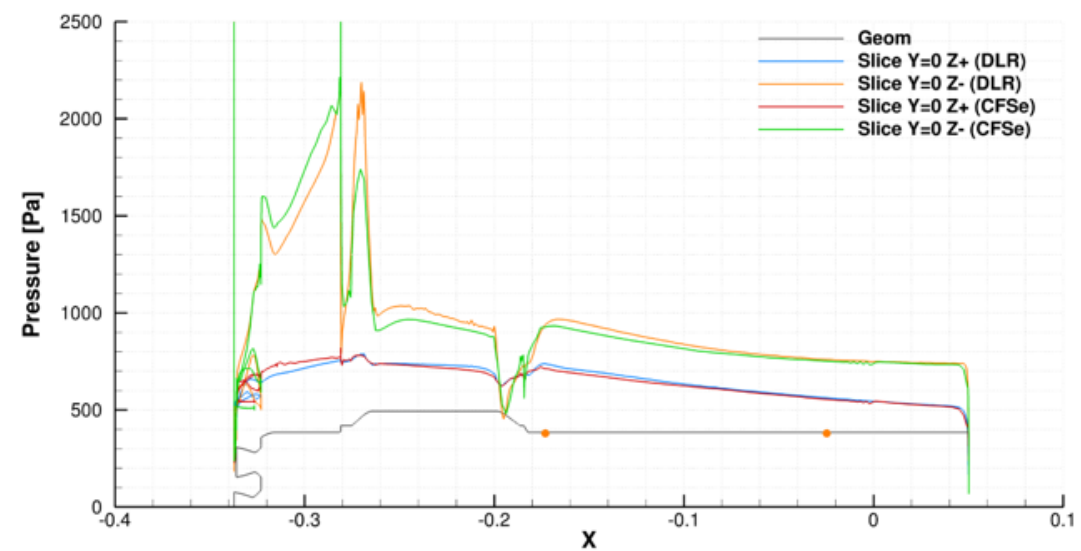

Fig. 25 Computed pressure along the body in the symmetry plane, central engine active, $A 0 A=10^{\circ}$.

Fig. 26 shows a comparison of the computed pressure on the body in the base region and on the landing legs for the calculation with an angle of attack of $0^{\circ}$. In the NSMB calculations the nozzles in the 2 symmetry planes are left open, and the engine conditions are imposed at the nozzle throat of the central engine.
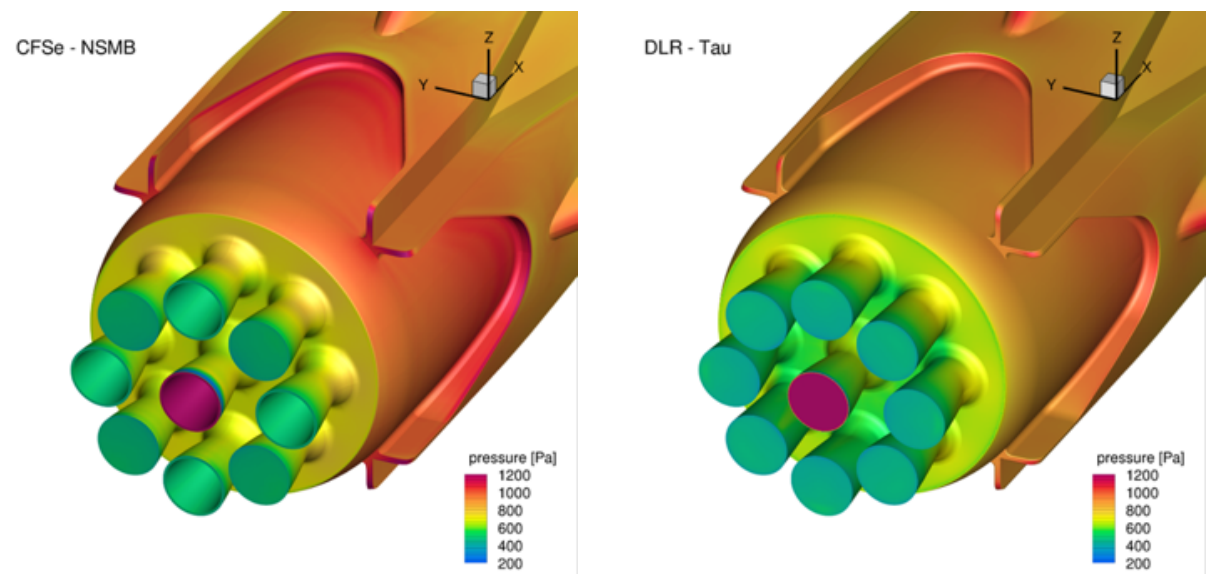

Fig. 26 Comparison pressure on the body in the base region, $\mathrm{AoA}=0^{\circ}$, left: NSMB calculation, right: TAU calculation. 
In the DLR calculations all nozzles are closed, and the engine conditions are imposed at the nozzle exit. One can observe differences in pressures on the base plate, and on the body in the regions of the landing legs, with NSMB predicting slightly higher pressures. But as already shown in Fig. 13, the plumes shapes are not exactly the same, and this will have an effect on the pressure levels in the base region. The origin of these differences is not clear, possibilities are the grid, the space discretization scheme, different variants of the Spalart-Allmaras turbulence models, the method the engine conditions are imposed etc. etc.

\section{3 engines active}

Fig. 27 shows the comparison wind tunnel data - CFD calculations for the cases with 3 active engines. For the case with an angle of attack $0^{\circ}$ there is a good agreement CFD-experiments for the first row of sensors (sensors 1114), but further downstream the CFD results predict higher pressures. For the case with an angle of attack $10^{\circ}$ there is a substantial difference in measured and computed pressure for sensor 14, which is on the first row, windward side. In the base region, and in particular for an angle of attack of $0^{\circ}$, large differences between measured and computed pressures can be observed.

Fig. 28 shows the comparison wind tunnel data with the CFD results obtained using the TAU solver for different turbulence models and using different grids. There are small differences visible when using the k- $\omega$ turbulence model instead of the Spalart-Allmaras turbulence model; at some pressure locations the results using the k- $\omega$ model are closer to the experimental result, at other locations it is the Spalart-Allmaras turbulence model. Comparing the coarse and fine grid results shows only small differences.
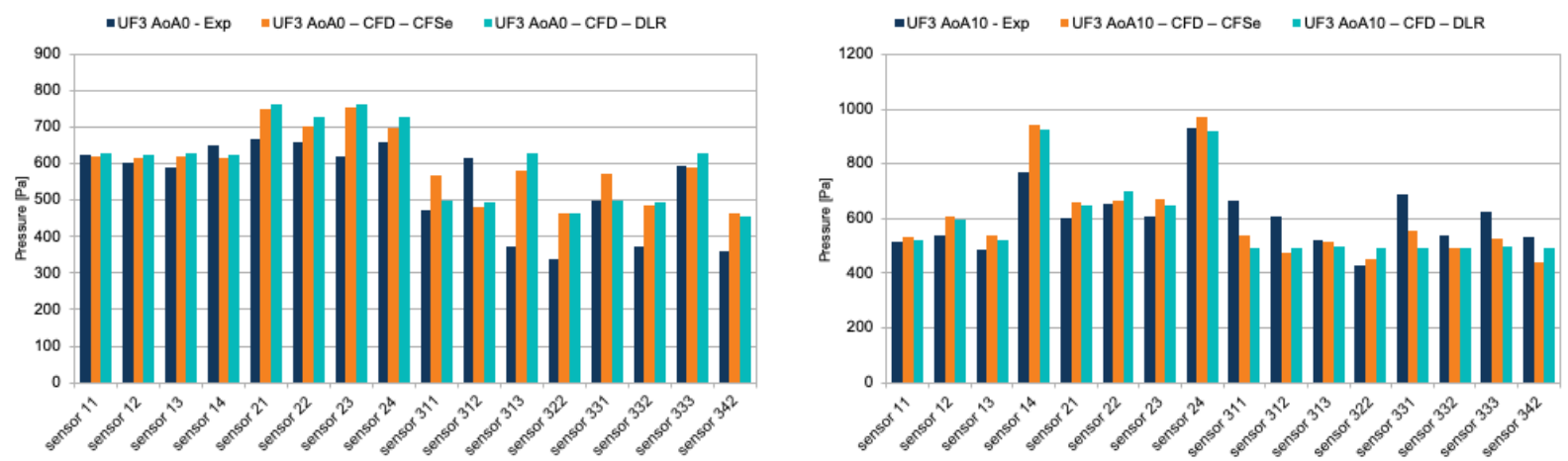

Fig. 27 Comparison pressure data Wind Tunnel Experiments and CFD, 3 active engines, left: $\mathbf{A o A}=0^{\circ}$, right: $\mathbf{A o A}=10^{\circ}$.
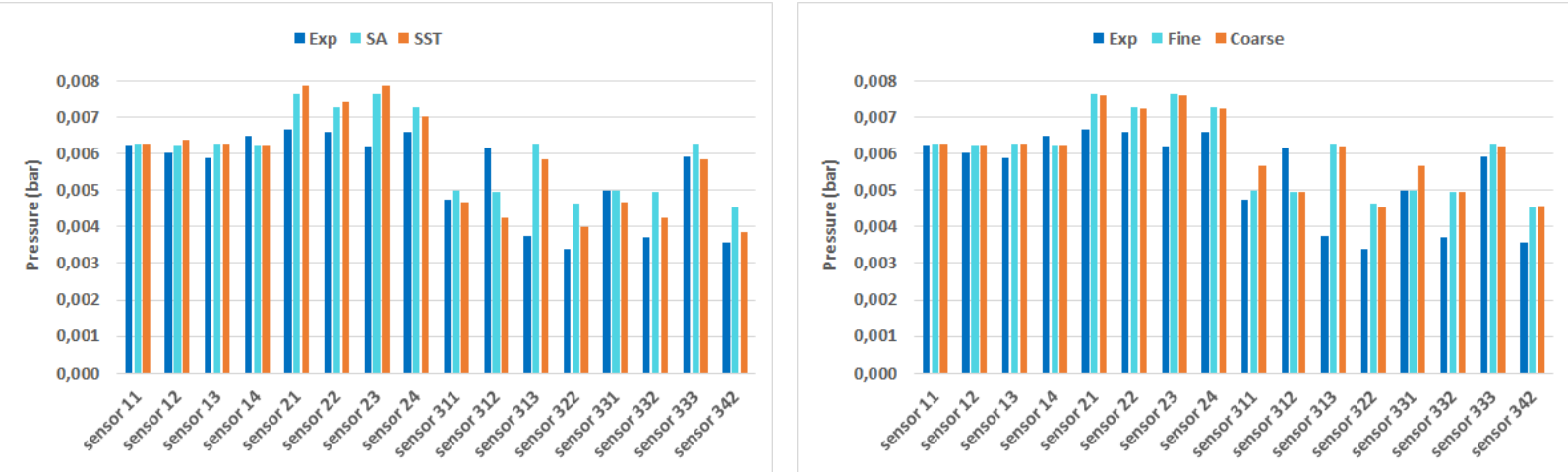

Fig. 28 Comparison pressure data Wind Tunnel Experiments and CFD, 3 active engines, left: Spalart-Allmaras and k- $\omega$ MSS turbulence models, right: coarse and fine grid.

\section{E. Synthesis comparison pressure data}

Fig. 29 presents the synthesis of the comparison of the pressure data, where for each pressure sensor the difference between measured and computed pressure, normalized by the computed pressure is plotted for all computed cases. The largest differences are found for the sensors 313 and 333, which are the sensors located on the body just downstream of the base region. It is not clear why the differences between computed and measured pressures are so 
large, in particular for the case with engine off. If one looks at all the computed cases, then one can observe that the case with 3 engines active and flying at a side slip angle of $10^{\circ}$ shows the largest difference between computed and measured pressures for most sensors on body and base region. In the base region (sensors 311, 312, 322, 331, 332, 342) almost all computed cases with 3 engines active show large differences, and this is for a substantial part due to the unsteady flow behavior observed in the experiments. If we ignore the 3 engines active cases, then we can see that on the body (sensors 11-24) differences between computed and measured pressures are below 15\%, although there are some outliers as for example sensor 13 for the case without engine and with $0^{\circ}$ angle of attack.

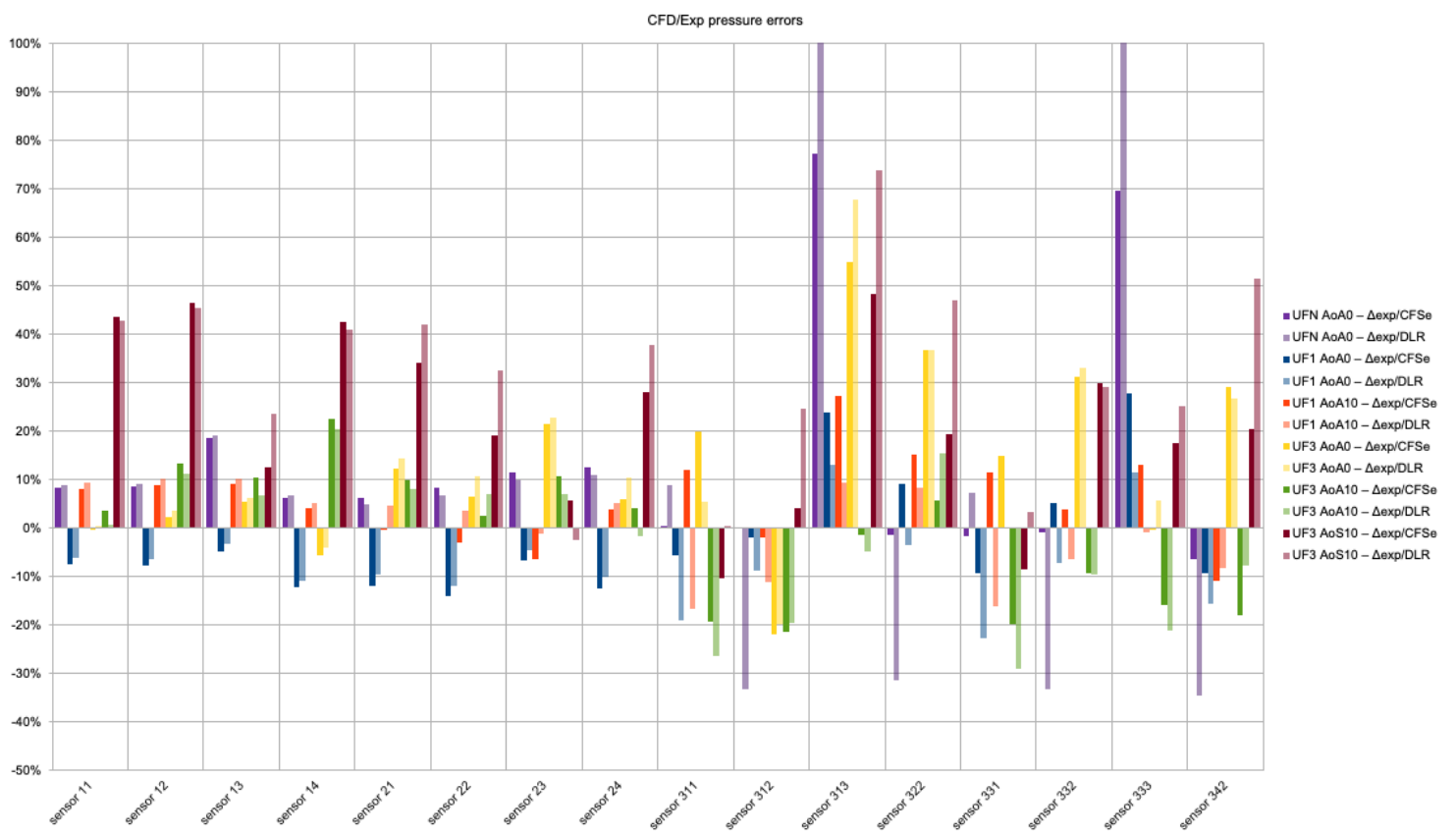

Fig. 29 Synthesis comparison pressure data.

\section{F. Flow structure in the base region with and without active engines}

Fig. 30 shows the pressure contours on the body together with the skin friction lines for the calculations without engine, with the central engine active, and with the 3 engines active. When the engine is switched off the bow shock is close to the body (see also Fig. 31), resulting in a high pressure on the base plane. As a result, the flow is pushed over the base plane. When one or three engines are active the flow structure is entirely different. When one engine is active several separation lines can be observed on the body just downstream of the base plane, marking the separation of the flow that goes in the direction of the plume and the flow that goes along the body. When three engines are active most of the flow along the body goes in the direction of the plume.

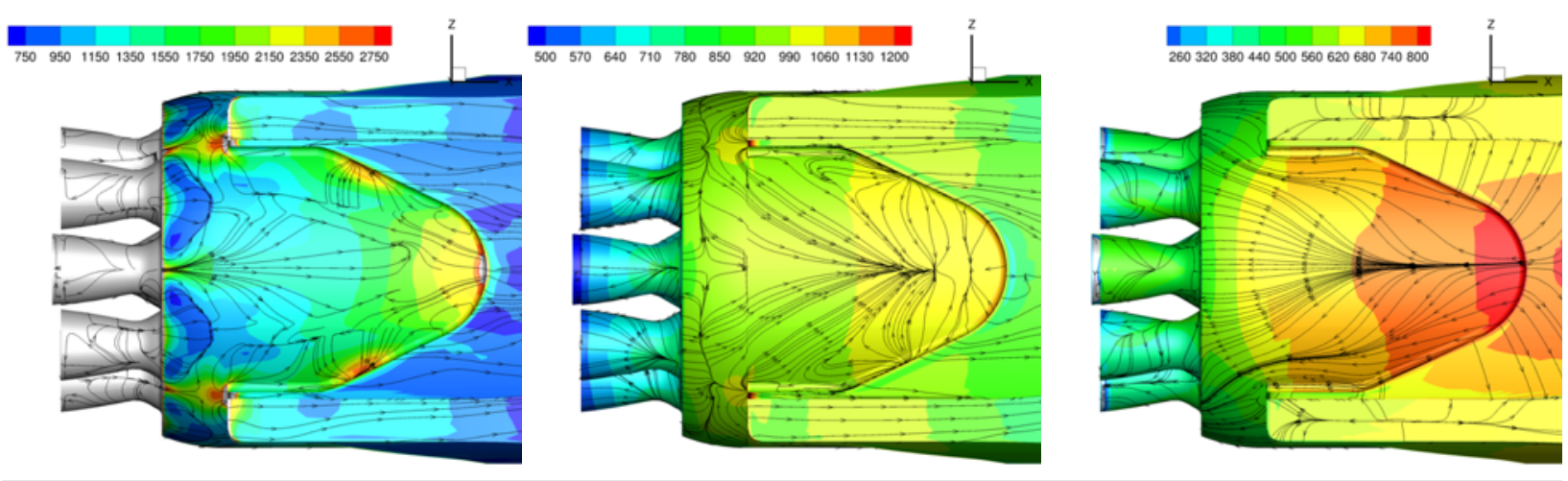

Fig. 30 Pressure contours (in Pa) and skin friction lines on the body, $\mathrm{AoA}=0^{\circ}$, left: Engine Off, middle: 1 Engine active, right: 3 Engines active. 
Fig. 31 shows the X-velocity in the symmetry plane, as well as the stream lines. When the engines are off flow separations can be seen inside and between the nozzles, and large separation bubbles can be seen when the flow goes over the base plane. The bow shock is also clearly visible. When the engines are active the situation changes, as shown before the bow shock is pushed away from the body, and large regions of separated flow are visible in the base region. When three engines are active (bottom row of pictures in Fig. 31) the flow is different in the plane with the active engines and in the plane with only the central engine active. Large flow separations are visible due to the suction of the engines.
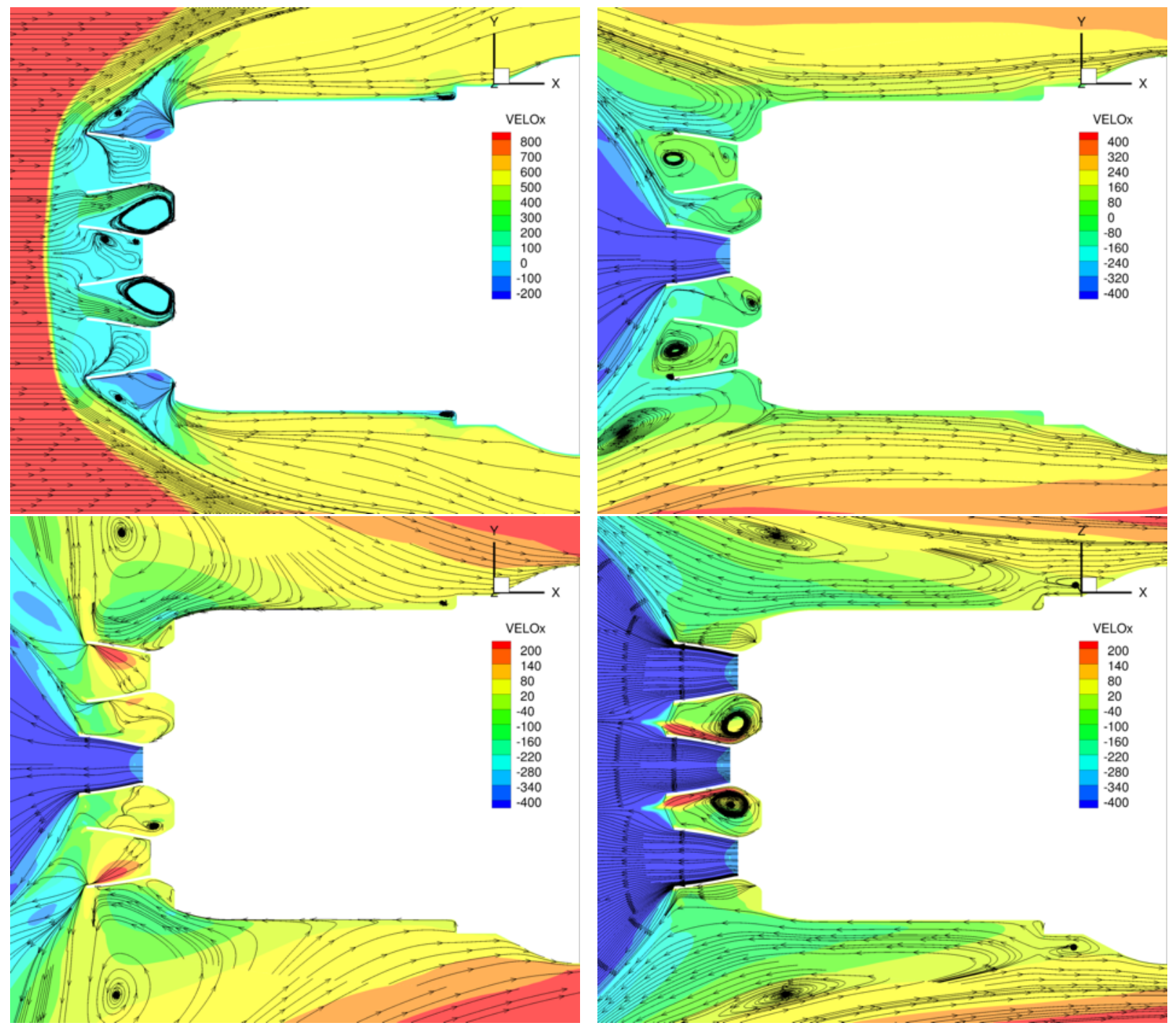

Fig. $31 \mathrm{X}$-velocity (in $\mathrm{m} / \mathrm{s}$ ) and streamlines in symmetry planes, $\mathbf{A o A}=0^{\circ}$. Top left: Engine Off, top right: 1 Engine active, bottom left: 3 Engines active, plane $z=0.0$, bottom right: 3 Engines active, plane $y=0.0$.

\section{Conclusions}

The paper presented a detailed analysis of Wind Tunnel Experiments and CFD calculations at hypersonic conditions for the first stage of a re-usable launcher configuration. The results of wind tunnel experiments were compared to CFD simulations using two different CFD codes. Experiments and CFD simulations were made with and without activated engines.

Comparing the results obtained using the two CFD codes showed a good agreement. The influence of the grid as well of the turbulence model were assessed, showing that this had only little influence on the results.

Comparison of the CFD calculations with the Schlieren pictures from the experiment showed in particular for the case with the central engine active small differences in the shock stand-off distance. The origin of this is not clear, 
several additional CFD simulations were made to assess the influence of the free stream Mach number and the total pressure in the nozzle, but no firm conclusion can be drawn. The precise position of the bow shock (as well as of the free stagnation point contact surface and the terminal shock Mach disk) is the results of a balance between the incoming hypersonic flow and the jet plume coming from the engine. The flow is complex, with several large separation zones that will influence this balance. The experiments for the case with 3 active engines showed an unsteady flow behavior, that was not observed in the CFD calculations. For this case it was also found that the space discretization scheme had an influence on the position of the bow shock wave, free stagnation point contact surface and the terminal shock Mach disk. A LES simulation was made to study this further, and showed that the bow shock wave was farther from the body than computed using RANS.

Measured pressures at several locations in the base region and along the body were compared with CFD results. The cases with 3 engines active showed unsteady flow behavior in the experimental results, resulting in large differences between computed and measured pressures for most pressure sensors. For 2 sensors located on the body, but close to the base region, substantial differences between computed and measured pressure values were observed. These two sensors are located in a region with important flow separations, which might be responsible for these differences. In general, the flow in the base region is complex with many flow separations, and differences between computed and measured pressures can be observed. Along the body the differences between computed and measured pressures are smaller.

\section{Acknowledgments}

This project has received funding from the European Union's Horizon 2020 research and innovation framework program under grant agreement No 821890. The authors are grateful to the partners of the RETALT consortium for their contributions and feedback.

\section{References}

[1] Marwege, A., Gülhan, A., Klevanski, J., Riehmer, J., Kirchheck, D., Karl, S., Bonetti, D., Vos, J., Jevons, M., Krammer, A., Carvalho, J., "Retro Propulsion Assisted Landing Technologies (RETALT): Current Status and Outlook of the EU Funded Project on Reusable Launch Vehicles.”, 70th International Astronautical Congress (IAC), Washington D.C., United States, 21-25 October 2019.

[2] Guelhan, A.; Marwege, A.; Klevanski, J.; Karl, S.; Bonetti, D.; Vos, J.; Jevons, M.; Krammer, A.; Carvalho, J., "RETALT RETro propulsion Assisted Landing Technologies", International Planetary Probe Workshop, Oxford, UK, 8-12 July 2019.

[3] De Zaiacomo G., Gonzalo Blanco A., Bunt R., Bonetti D., "Mission Engineering for the RETALT VTVL Launcher", CEAS Space Journal Special Issue, (2022).

[4] Niezgodka, F.-J. "Der Hyperschallwindkanal H2K des DLR in Köln-Porz (Stand 2000)”, DLR-Mitt. 2001-01, Cologne.DOI: 10.13009/ EUCASS2017-680, 2001.

[5] Esch, H., “Die 0.6-m x 0.6-m - „Trisonische Meßstrecke (TMK) der DFVLR in Köln-Porz (Stand 1986)“"” DFVLR-Mitt. 8621, Cologne. 1986.

[6] Seltner Patrick M., Willems S., Gülhan A., "Experimental Determination of Aerodynamic Coefficients of Simple-Shaped Bodies Free-Flying in Hypersonic Flow", HiSST: International Conference on High-Speed Vehicle Science Technology, 2629 November 2018, Moscow, Russia.

[7] Hoarau, Y., Pena, D., Vos, J.B., Charbonnier, D., Gehri, A., Braza ,M., Deloze, T., Laurendeau, E., "Recent Developments of the Navier Stokes Multi Block (NSMB) CFD solver", AIAA Paper 2016-2056, 2016.

[8] Spalart, P.R., Allmaras, S.R., “A One-Equation Turbulence Model for Aerodynamic Flows”, AIAA Paper 92-0439, Jan. 1992.

[9] Menter, F.R., "Influence of freestream values on the k- $\omega$ turbulence model predictions", AIAA Journal, Vol. 30, (1992).

[10] Schwamborn, D., Gerhold, T., and Heinrich, R., "The DLR TAU-Code: Recent Applications in Research and Industry," European Conference on Computational Fluid Dynamics ECCOMAS CFD 2006, Conference Proceeding Series, Sept. 2006.

[11] Langer, S., Schwöppe, A., and Kroll, N., "The DLR Flow Solver TAU-Status and Recent Algorithmic Developments," AIAA Paper 2014-0080, 2014

[12] Eisfeld, B., "Numerical simulation of aerodynamic problems with a Reynolds stress turbulence model," New Results in Numerical and Experimental Fluid Mechanics V, edited by H.-J. Rath, C. Holze, H.-J. Heinemann, R. Henke, and H. Hönlinger, Vol. 92 of Notes on Numerical Fluid Mechanics and Multidisciplinary Design (NNFM), Springer Berlin Heidelberg, 2006, pp., 413-421.

[13] Bottin, B., "Aerothermodynamic model of an inductively-coupled plasma wind tunnel", PhD-Thesis, University of Liege, (1999).

[14] Gordon, S., McBride, B.J., "Computer program for calculation of complex chemical equilibrium compositions and applications”, NASA Reference Publication 1311 (1994).

[15] Gutsche, K., Marwege, A., Gülhan, A., "Similarity and Key Parameters of Retropropulsion Assisted Deceleration in Hypersonic Wind Tunnels", Journal of Spacecraft and Rockets, May 2021, https://doi.org/10.2514/1.A34910. 